Journal of Machine Engineering, 2021, Vol. 21, No. 1, 22-55

ISSN 1895-7595 (Print) ISSN 2391-8071 (Online)

Received: 10 November 2020 / Accepted: 28 January 2021 / Published online: 29 March 2021

machining, aerospace materials, nickel and titanium alloys,

composites

\author{
Krzysztof JEMIELNIAK ${ }^{1 *}$
}

\title{
REVIEW OF NEW DEVELOPMENTS IN MACHINING OF AEROSPACE MATERIALS
}

\begin{abstract}
The paper presents an update of the recent literature on advances in machining of difficult to machine materials such as nickel and titanium-based alloys, and composites used in aeroengine and aerostructure applications. The review covers the following issues: advances in high-performance cooling techniques as cryogenic machining, minimum quantity lubrication, the combination of MQL and cryogenic cooling, and high-pressure lubricoolant supply and hybrid cutting processes - vibration assisted machining (both low and high frequency), laser, plasma and EDM assisted machining. Examples of applications in industrial processes are also given.
\end{abstract}

\section{INTRODUCTION}

Super alloys, such as titanium and nickel alloys, have excellent mechanical and chemical properties at high temperature, which has been widely applied in aerospace, ocean, and chemical industries. However, the super high temperature properties lead to their poor machinability and machined surface integrity. Variation of chip thickness, high heat stress, high pressure loads, spring back, and residual stress are responsible for higher tool wear and worse machined surface integrity. Composite materials like carbon fiber reinforced polymer (CFRP) are introduced in aircraft design and manufacturing for improved performance (lightweight and strength), reduced life cycle and maintenance cost and lower production cost, quality robustness and reduced lead time. Failures that arise during composite materials machinability reduce the strength and fatigue life of the material. The most serious failure arising from the drilling of composite materials is reported to be delamination on hole surfaces. To address these problems, high performance cooling techniques and hybrid cutting processes are applied.

Lowering the temperature in the cutting zone is a necessary condition to obtain an acceptable cutting tool life and the quality of the surface integrity. Conventional flood cooling is hazardous for health and the environment. Therefore, introducing new environ-

\footnotetext{
${ }^{1}$ Faculty of Production Engineering, Warsaw University of Technology, Warsaw, Poland

*E-mail: krzysztof.jemielniak@pw.edu.pl https://doi.org/10.36897/jme/132905
} 
mentally friendly lubrication and cooling techniques is extremely required, especially in machining of difficult-to-cut materials. Cryogenic cooling is effective alternative for enhancing the machinability and dissipating the generated heat at the cutting zone as it affects the properties of the cutting tool and workpiece using a super cold medium like liquid nitrogen $\left(\mathrm{LN}_{2}\right)$ or carbon dioxide $\left(\mathrm{LCO}_{2}\right)$. Another environmentally friendly technology is MQL where a fine mist is applied to the cutting zone using the optimal amount of cutting fluid with compressed air. Especially promising are nanofluids - the dispersion of non-metallic/metallic nano-additives with size less than $100 \mathrm{~nm}$ into the base fluid as they have superior cooling characteristics due to their advanced capabilities to extract the generated heat.

Most widely applied hybrid processes are laser assisted cutting, vibration assisted cutting. Due to the combined action of processes, cutting forces and tool wear could be reduced and surface finish improved compared to conventional machining.

As the above issues are in the focus of scientists worldwide, there are many excellent review articles on earlier achievements concerning them, e.g. [1-9]. Therefore, this paper presents an overview only of the latest (2018-2020) advances in innovative machining of aerospace alloys and composites currently used in aeroengine and aerostructure applications.

\section{HIGH PERFORMANCE COOLING TECHNIQUES}

\subsection{CRYOGENIC MACHINING}

The most important challenge when machining difficult-to-cut alloys used in critical aerospace applications is to increase tool life and improve the surface integrity of the component. Titanium and nickel alloys are optimal metals to use in aircraft components. They are generally accepted as difficult to-machine materials, because of their poor thermal conductivity. The selection of coolant and machining conditions is crucial for better performance. Problems with conventional coolant are failure of lubrication at higher metal removal and cause environmental pollution [10]. Conventional flood cooling is "ineffective" method to remove heat properly as heat evacuation is mainly dependent on the temperature difference. The emulsion remains in the liquid state during cooling, therefore it stays in contact with the heater or the workpiece surface for a longer time [11, 12]. An enhanced heat transfer during cutting is necessary to reduce the high cutting temperature and result in improved machining performance. In this context, cryogenic machining is a promising approach that enhances cooling efficiency either with liquid nitrogen $\mathrm{LN}_{2}$ or liquid carbon dioxide $\mathrm{LCO}_{2}$. The heat-evacuation mechanism of $\mathrm{LN}_{2}$ and $\mathrm{LCO}_{2}$ mainly depends on the heat absorption due to the phase transformation of the cryogen. Furthermore, cryogenic machining recently gained interest as a clean and economical cooling technique [13]. It becomes a promising candidate for applications that involve the aggressive metal removal, especially for hard-to-cut material. Overview of major cryogenic manufacturing processes, summarizing the state-of-the-art and significant developments during the last few decades can be found in [14]. Here only newest ideas and results are presented. 
Cryogenic cooling greatly influences the quality of machined surface and brings down the tool wear by decreasing the temperature on the cutting zone wear (see e.g., Fig. 1 and Fig. 2). These effects known already for a long time are confirmed also in the latest literature [10], [15, 16].
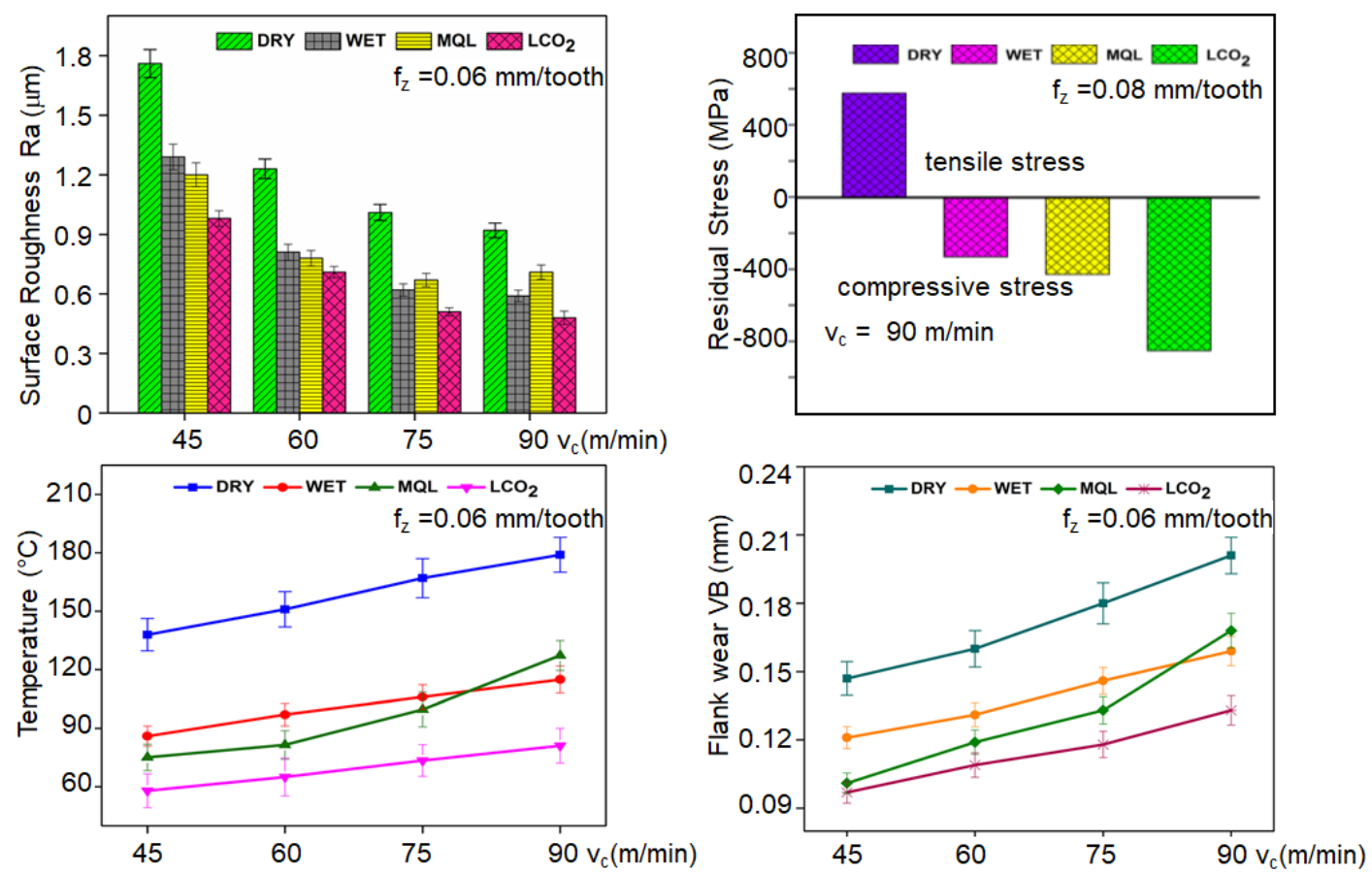

Fig. 1. Results of $\mathrm{LCO}_{2}$ cooling application in milling of Nimonic 80A [10]
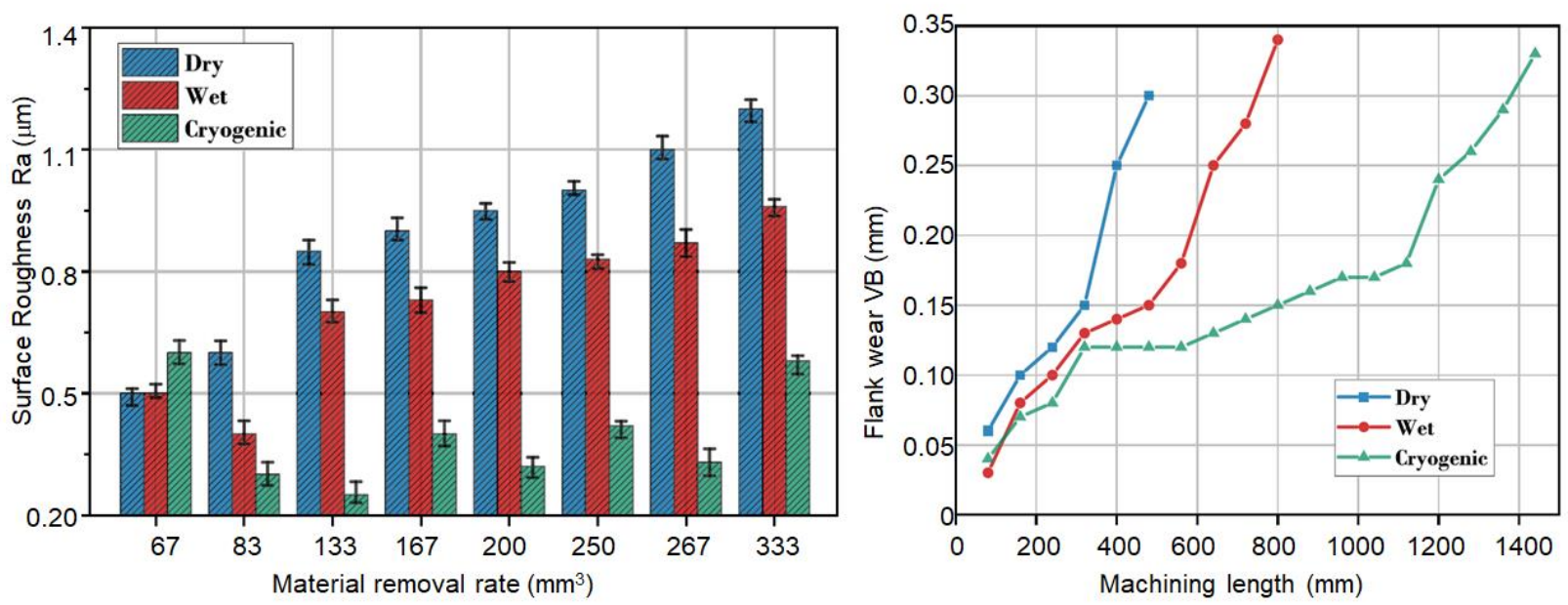

Fig. 2. Ra variation at different material removal rates values and flank wear behavior for turning of Ti6Al4V under altered cutting conditions [16]

However, some studies have shown that while conventional lubrication and $\mathrm{LCO}_{2}$ cooling allowed to obtain similar machining time, tool wear and surface finish, $\mathrm{LN}_{2}$ turning of Inconel 718 resulted in the lowest tool life as well as the poorest surface finish. Still, compared to conventional lubrication, both cryogenic cooling showed better results with respect to residual stress profiles along the machined surfaces [17]. 
The excessive workpiece cooling by $\mathrm{LN}_{2}$ may cause a material embrittlement/hardening with consequent increase of the abrasion effect, although the thermally activated wear mechanisms are reduced limiting the crater wear formation. On the contrary, the gaseous $\mathrm{N}_{2}$ cooled at $-100^{\circ} \mathrm{C} \div 150^{\circ} \mathrm{C}$ allow reducing the heat generated during the cutting process, thus limiting the crater wear, but without modifying the initial material characteristics and thus limiting also the flank wear. Therefore, use of cooled gaseous $\mathrm{N}_{2}$ represents the best strategy for semi finishing turning of the Ti6Al4V, since it minimizes the surface defects and surface microstructural alterations ensuring, at the same time, a significant compressive state of residual stresses that can improve the fatigue resistance of the final product [18-19], (Fig. 3).
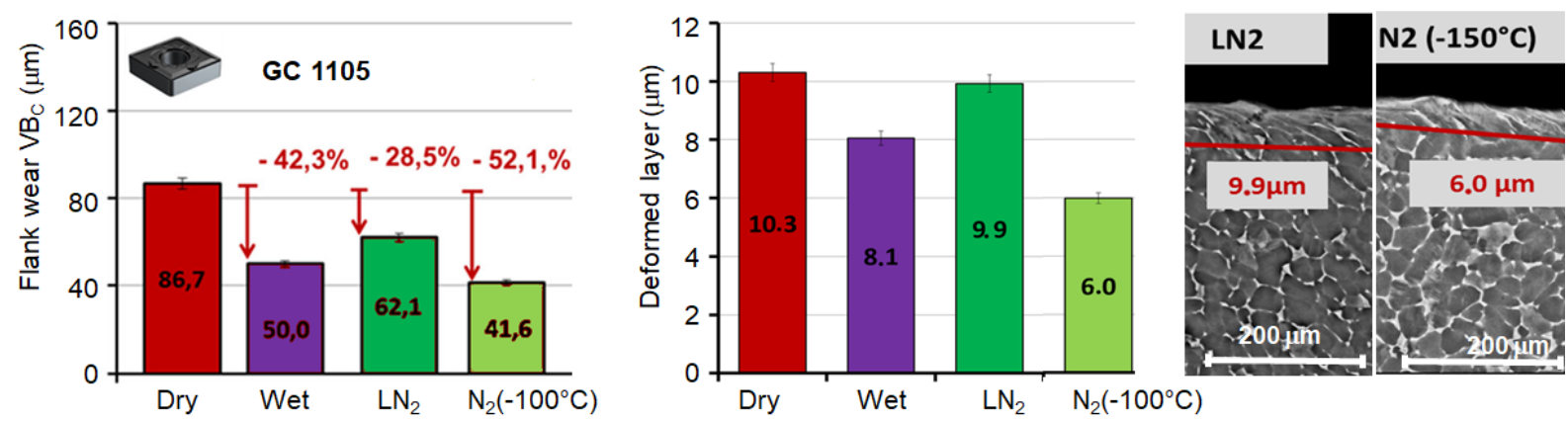

Fig. 3. Tool flank wear and thickness of the machining-altered layer as a function of the adopted cooling strategies during semi finishing turning of the Ti6Al4V [18-19]

Also, during rough turning of Ti6Al4V application of metalworking fluid (MWF - water and polyhydric alcohols) cooled down to $-30^{\circ} \mathrm{C}$, resulted in lower tool wear and favorable chips compared with emulsion, $\mathrm{CO}_{2}, \mathrm{LN}_{2}$, and dry machining [20].

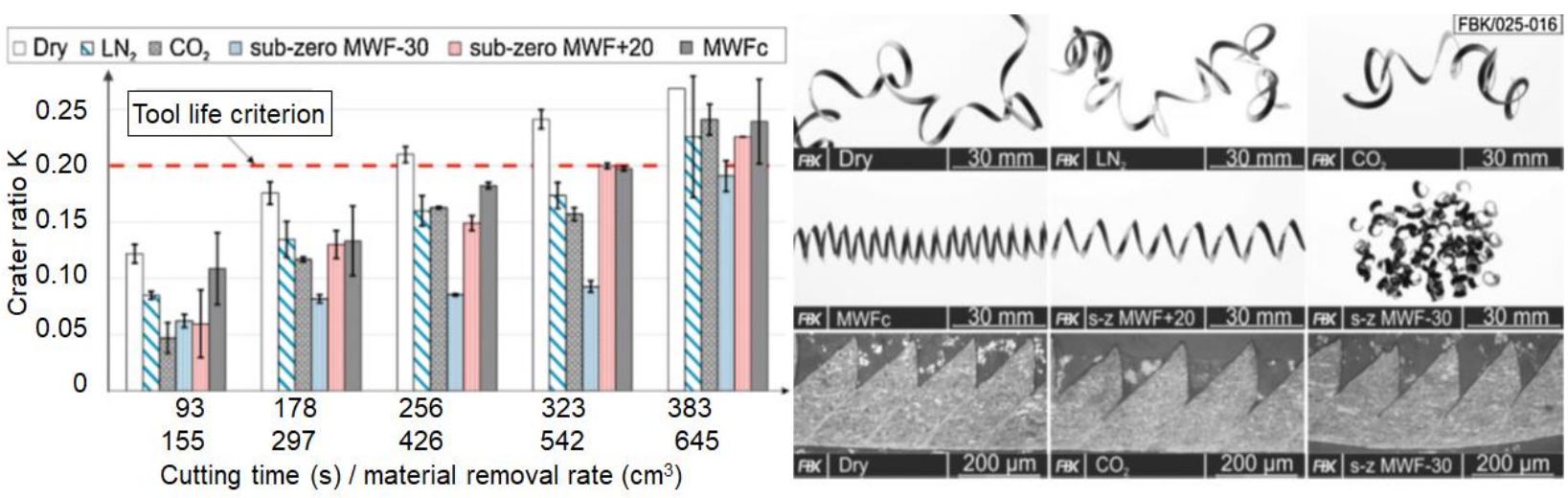

Fig. 4. Crater ratio as a function of cutting time/travel path and generated chips and etched longitudinal cut during rough turning of Ti6Al4V [20]

Another way to maintain the normal temperature of the Ti6Al4V workpiece, hence prevent it from hardening is indirect cryogenic cooling where the liquid nitrogen is supplied only to cooled down the tool without to be exposed to the workpiece. 
In cryogenic machining, $\mathrm{LN}_{2}$ inevitably tends to evaporate within the supply channels. This induces process variations and hinders the use of nitrogen cooling in commercial applications. As a countermeasure insulated pipes, insulated tools or a phase separator are usually used, however their effectiveness is questionable. Attractive alternative is subcooling, a known principle when $\mathrm{LN}_{2}$ is used to cool silicone chips in microelectronics which was recently proposed in the application of cryogenic cutting [21], (Fig. 5).
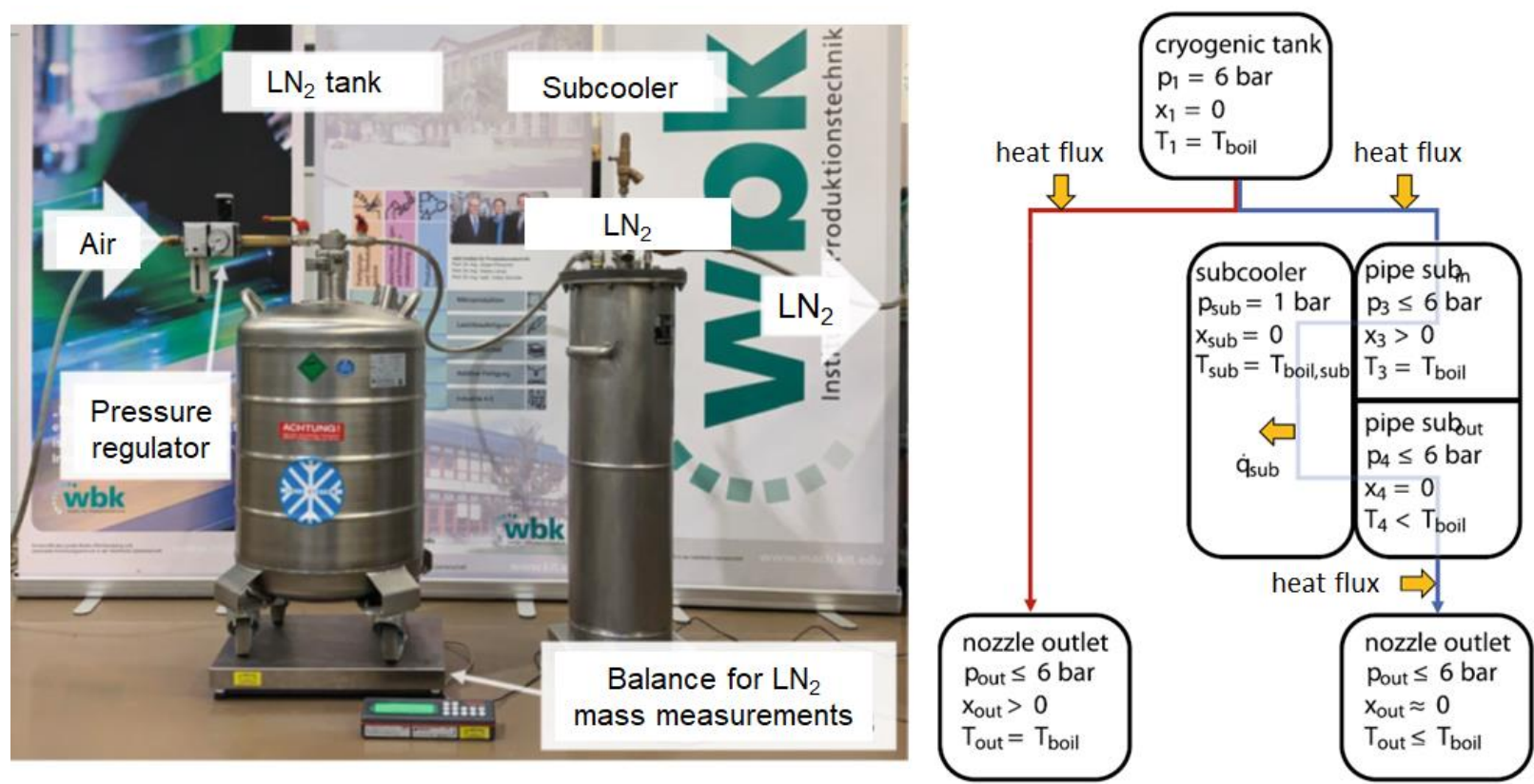

Fig. 5. Setup of the nitrogen supply with subcooler and comparison of standard nitrogen supply (red line) and the subcooler case (blue line) [21]

Subcooler usage decreases the nitrogen evaporation rate and accelerates the initial cooling of the supply system. Therefore, increased mass flow rates result at the same working pressures, compared to systems without subcooling. Without subcooling, the tested working pressures between 5 and 7 bar were not suited to adjust the mean maximum temperature in a reliable manner. However, with subcooling, a clear trend in the cutting temperatures is seen between 4 and 7 bar. Consequently, a convenient adjustment of the tool temperature by the working pressure is only possible when using a subcooler. This technique could be used to easily adjust the cooling effect and the LN2 consumption to different machining parameters or workpiece materials.

Cutting temperature plays a decisive role in determining machined carbon fiber reinforced polymer (CFRP) surface quality. Cutting area temperature can reach around $200^{\circ} \mathrm{C} \div 400^{\circ} \mathrm{C}$, which is larger than the matrix (epoxy) glass transition temperature $80^{\circ} \mathrm{C} \div 180^{\circ} \mathrm{C}$. This can lead to the softening and thermal degradation of the matrix material and the debonding of the fibers-matrix. Sometimes, high cutting temperature also causes burning of the matrix. Thermal degradation of cured epoxy resin affects the machining quality, which can also reduce the tensile strength of CFRP machined parts. Traditional coolants affect the mechanical integrity and dimensional accuracy of composite structures 
due to absorption of moisture. Recently, the use of cryogenic cooling for machining of composites gains increasing interest. Significant decrease in surface damage and roughness and cutting temperature when cryogenic milling of unidirectional carbon fiber reinforced plastics (UD-CFRP) laminates was observed despite an increase in resultant forces for all fiber orientations [22].

Cryogenic $\left(\mathrm{LN}_{2}\right)$ machining of the small diameter inclined holes $\left(30^{\circ}, 60^{\circ}\right.$, and $\left.90^{\circ}\right)$ drilled in CFRP generated at least $40 \%$ higher thrust forces compared to dry cutting (Fig. 6). This is primarily due to uneven chip load at primary and chisel edges of the drill at acute inclinations. This causes high tool deflection and plowing effect resulting in higher thrust forces and much wider plow tracks aiding in initiation of matrix/fiber failure mechanisms. Surface quality under cryogenic was enhanced than dry cutting with reduced matrix transverse cracking that helped suppress the fiber debonding and pull out. This mechanism also aids to minimize stress concentration regions along matrix/fiber interfaces due to promotion of sliding shear of carbon fibers and reduction of fracture mode III out of plane peel-up and push-down interlaminar delamination (Fig. 7). As a result, cryogenic machining delivers the required inclined hole output by significantly decreasing the dimensional errors when related with dry cutting [23].
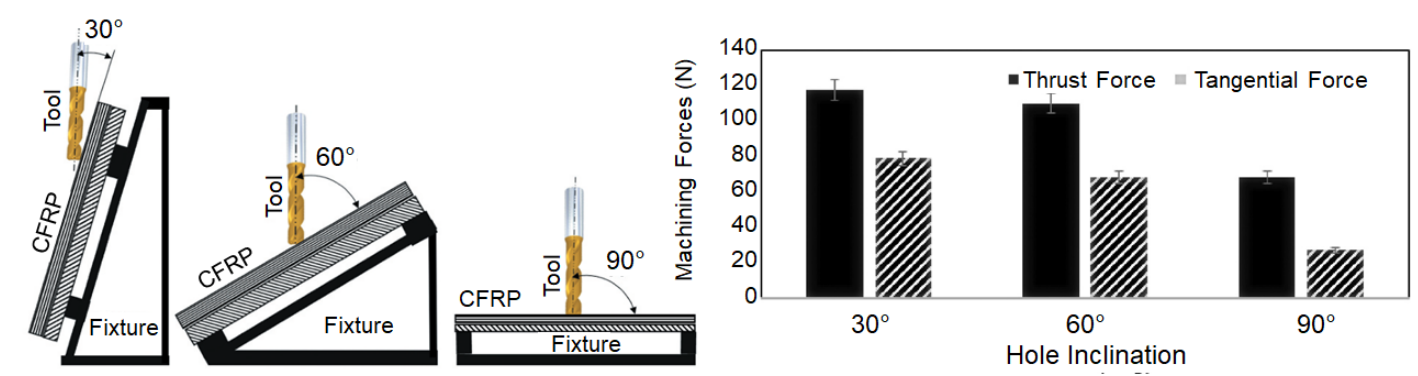

Fig. 6. CFRP ply orientations and machining forces at different hole inclinations $\left(v_{c}=45 \mathrm{~m} / \mathrm{min}, f=250 \mathrm{~mm} / \mathrm{min}\right)$ [23]
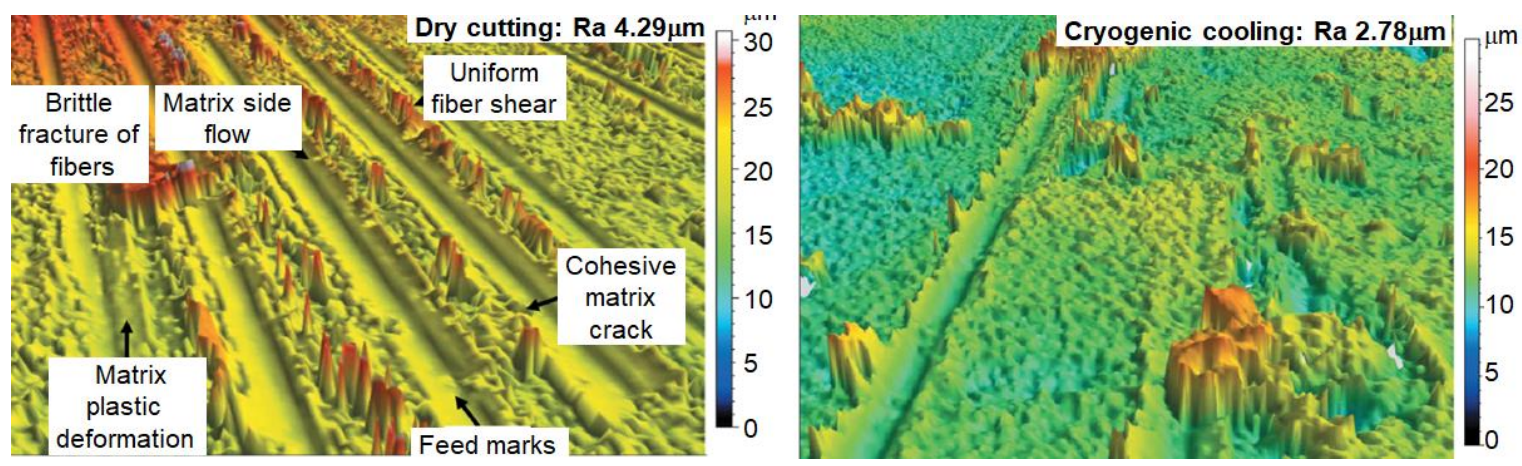

Fig. 7. Confocal surface analysis of holes drilled at $30^{\circ}$ inclination $\left(v_{c}=45 \mathrm{~m} / \mathrm{min}, f=250 \mathrm{~mm} / \mathrm{min}\right)$ [23]

\subsection{MINIMUM QUANTITY LUBRICATION - MQL}

Flood cooling is a typical industrial cooling strategy to dissipate the high temperatures generated during machining of difficult-to-cut materials. The use of flood coolant has increased environmental and health concerns, which require different alternatives. 
A minimum quantity lubrication (MQL) has been successfully introduced as an acceptable cooling strategy. For example, comparative evaluation of modified high oleic soybean oil (HOSO) flow rate in face milling of Inconel 718 using inexpensive shell mill-coated carbide inserts and conventional flood cooling show that MQL oil flow rate has a major impact tool life and resultant cutting force reaching optimum at $70 \mathrm{ml} / \mathrm{h}$. Increasing MQL flow rate improves surface roughness and reduces tool wear by providing enough, thin lubrication film, but also leads to an increase in chip affinity and the formation of large built-up edges (BUEs) Fig. 8. [25].
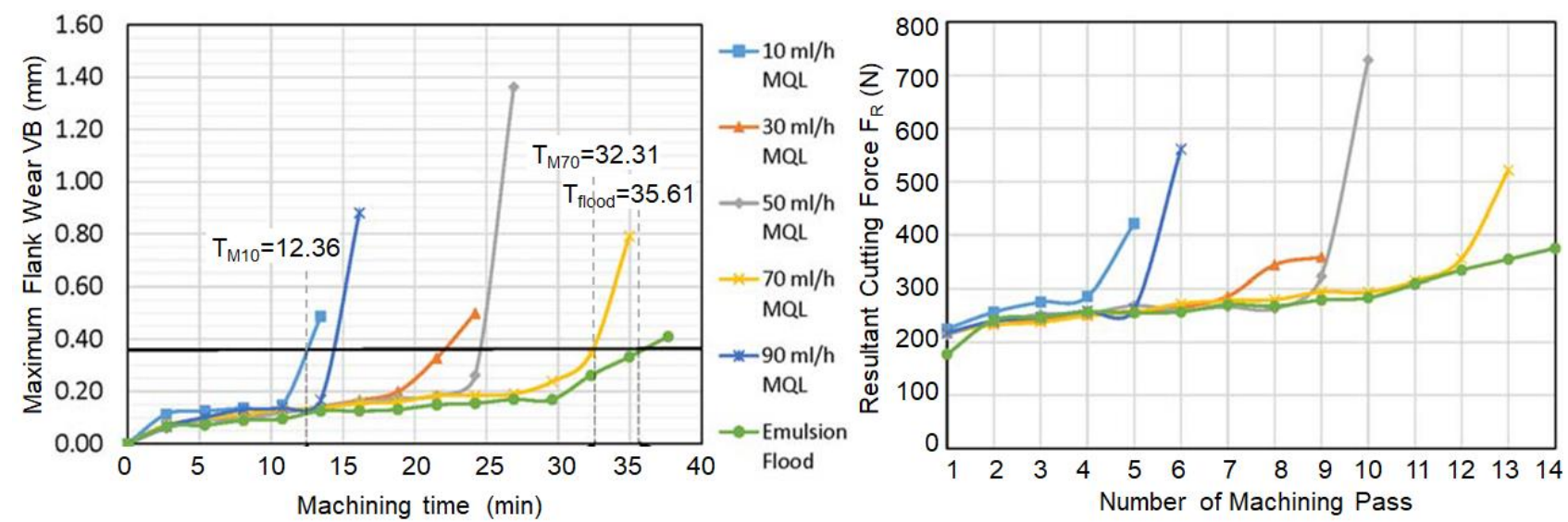

Fig. 8. Maximum flank wear vs. machining time and resultant cutting force vs. machining pass from the 1 st to final pass under cooling-lubrication strategies [24]

Comprehensive review of the literature available on the use of the MQL technique during processing of difficult-to-cut materials can be found in [6]. In general, there are comparable results for MQL and flood conditions in terms of tool wear rate and tool life. Most studies demonstrate that the MQL brought a remarkable improvement in the machining performance when compared to dry conditions during various machining processes. Therefore, it can be stated that the MQL technique is an effective alternative approach to the conventional cooling condition. However, the MQL heat dissipation potential is much lower than with flood coolant. MQL-nano-cutting fluid is one of the suggested techniques to further improve the performance of MQL, especially when processing difficult-to-cut materials. A nano-fluid is a dispersion of metallic/non-metallic nanoparticles or nanofibers of a specific size less than $100 \mathrm{~nm}$ in a base cutting fluid. Nanoparticles can drastically enhance the heat transfer ability of metalworking fluids [25]. Nano-additives can be divided into several types, which are non-metallic, mixed metallic, carbon and ceramic nanoparticles. Comparison of results obtained while using cottonseed oil modified with six different nanoparticles $\left(\mathrm{Al}_{2} \mathrm{O}_{3}, \mathrm{MoS}_{2}, \mathrm{SiO}_{2}\right.$, carbon nanotubes - CNT, $\mathrm{SiC}$ and graphite) at the mass ratio of $1.5 \%$ as MQL coolant for milling of Ti6Al4V are presented in Fig. 9 [25]. The lowest milling force in the $\mathrm{X}$ direction was obtained with $\mathrm{Al}_{2} \mathrm{O}_{3}$ followed by CNT. This effect will attenuate the generation of cutting heat and consequently decreases cutting heat generation, and milling temperature. Fig. 9 shows a drastic increase in temperature under milling with CNT nanofluid despite cutting force not high. It may be attributed to CNT aggregation, which 
reduced heat dissipation capacity. Workpiece temperatures under milling with other nanofluids were less than $100^{\circ} \mathrm{C}$ indicating high thermal conductivity and cooling capacity. The large milling force and low workpiece temperature obtained during milling with $\mathrm{SiO}_{2}$ nanofluid indicate that $\mathrm{SiO}_{2}$ nanoparticles had the strongest cooling capacity among the tested nanoparticles. The lowest $\mathrm{Ra}$ value was obtained with $\mathrm{Al}_{2} \mathrm{O}_{3}$ nanofluid $(66.7 \%$ lower than that of acquired under milling with pure cottonseed oil) followed by that obtained under milling with $\mathrm{SiO}_{2}$ nanofluid. Given that $\mathrm{Al}_{2} \mathrm{O}_{3}$ and $\mathrm{SiO}_{2}$ nanoparticles demonstrated the best cooling performance, they are highly suitable as additives for the base oil for MQL.
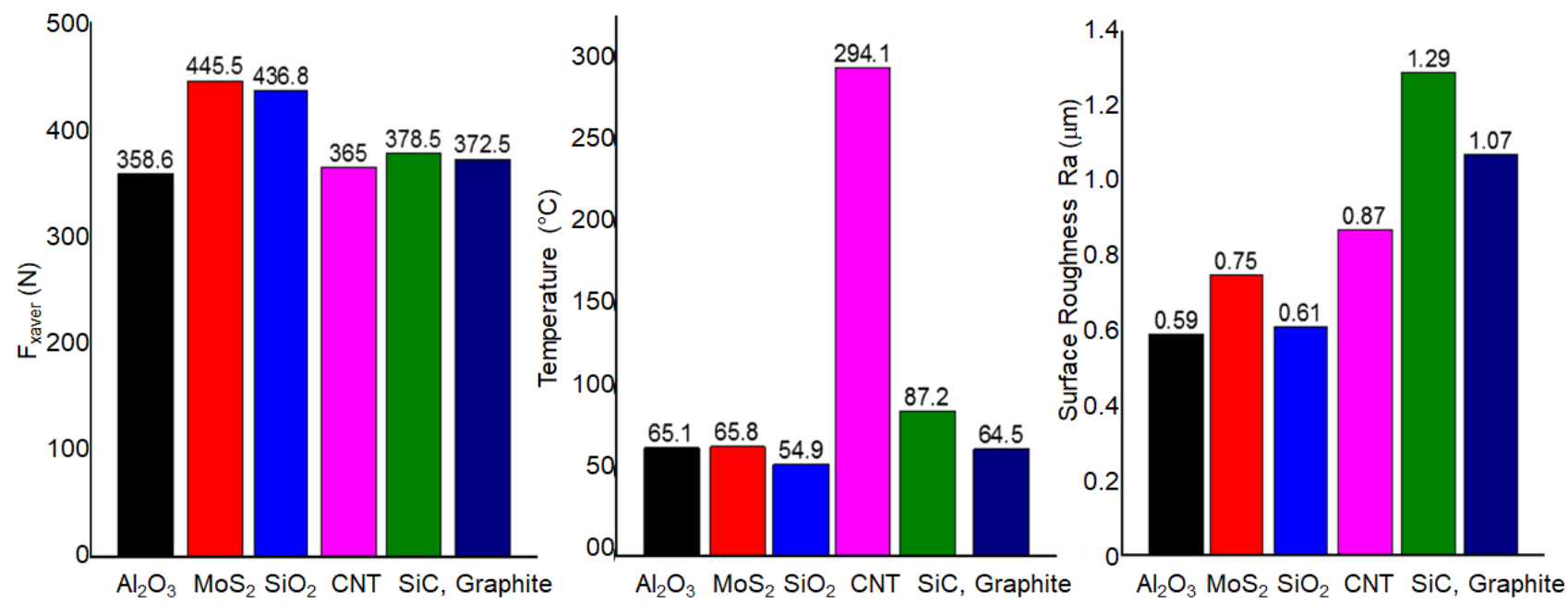

Fig. 9. Comparison of mean values of milling force, the peak temperature and surface roughness values of workpieces under MQL with different nanoparticles under milling of Ti6A14V [25]

Application of nano-cutting fluids with multi-walled carbon nanotubes (MWCNTs) and aluminum oxide $\left(\mathrm{Al}_{2} \mathrm{O}\right)$ gamma nanoparticles utilized as nano-additives during turning of Inconel 718 gives better results compared MQL without any nano-additives. Significant changes in modes of tool wear and improvement in the intensity of wear progression have been observed when using nano-fluids. Lower deformed chip thickness has been observed, when nano-fluids are used, which is attributed to the increase in the shear angle (Fig. 10).

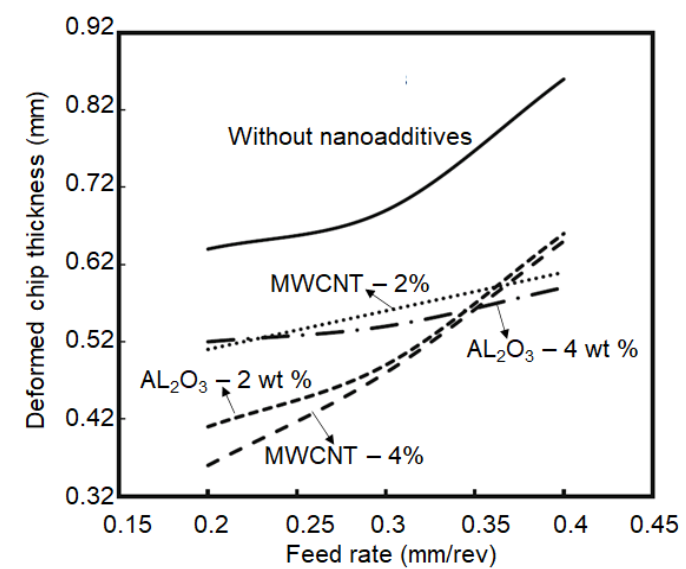

Fig.10. Effect of feed rate on chip thickness during machining of Inconel 718 with/without nano-fluids [26] 
Consequently, lower cutting forces are generated due to the increase in the shear angle and effective dissipation of heat which prevents the chip welding tendency while cutting without nano-additives [26]. Also, addition of dispersed multi-walled carbon nanotubes into vegetable oil in turning of Ti6Al4V reduces the power consumption and flank wear [26].

Addition of $\mathrm{MoS}_{2}$ as solid lubricant in vegetal base oil applied by MQL when turning Inconel 718, with whisker-reinforced ceramic cutting tools substantially improved tool life, the surface quality and $\mathrm{Ra}$. Better results were found using vegetal base oil $+20 \%$ of graphite; as to the cutting force, the lubricants produced the lowest values [27] (Fig. 11).
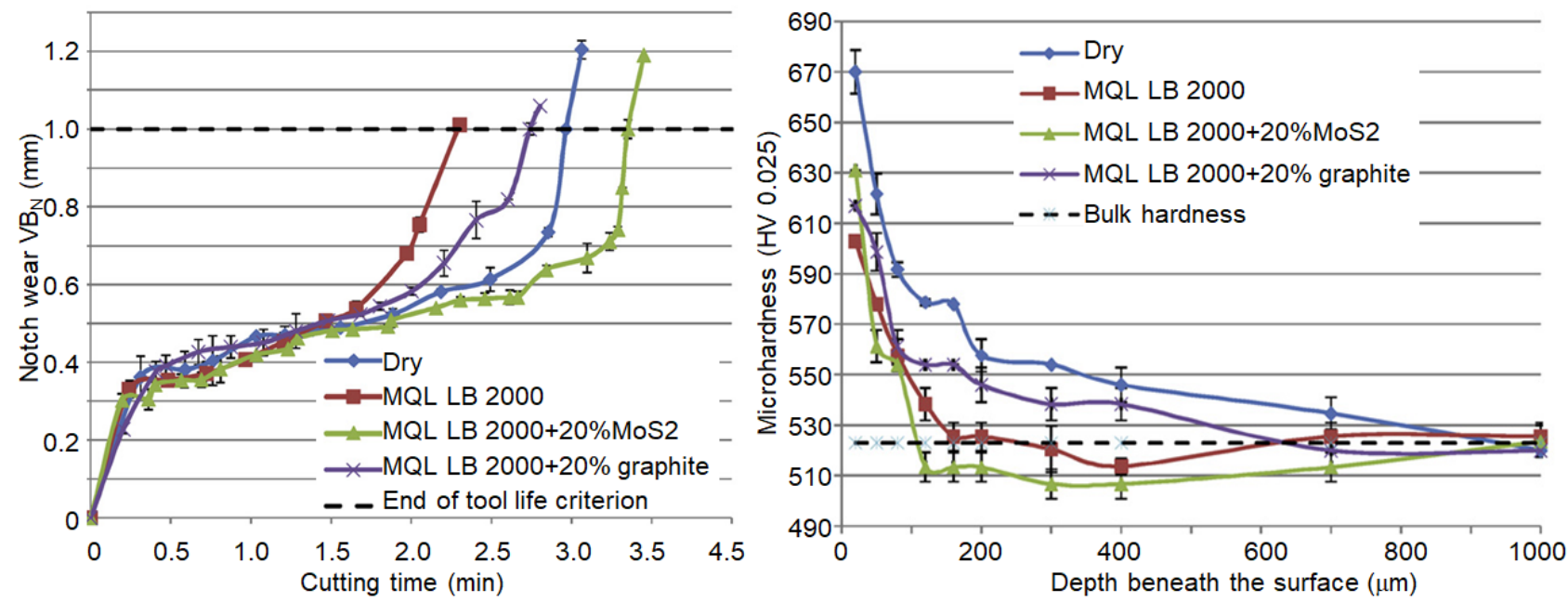

Fig. 11. Notch wear vs time for machining Inconel 718 and workpiece subsurface microhardness under various lubri-cooling conditions for worn edge $\left(v_{c}=250 \mathrm{~m} / \mathrm{min}, f=0.1 \mathrm{~mm} a p=0.5 \mathrm{~mm}\right)$ [27]

Application $\mathrm{MoS}_{2}$ with particle size of $10-15 \mu \mathrm{m}$ and graphite powder with a particle size of 30-45 $\mu \mathrm{m}$ in the MQL aggressive machining of Inconel 718 have shown 50-65\% less flank wear, and 39-51\% less surface roughness due to solid lubricants at a tool-chip interface that limited notching and fracture of tool edge compared to dry machining [28] (Fig. 12).
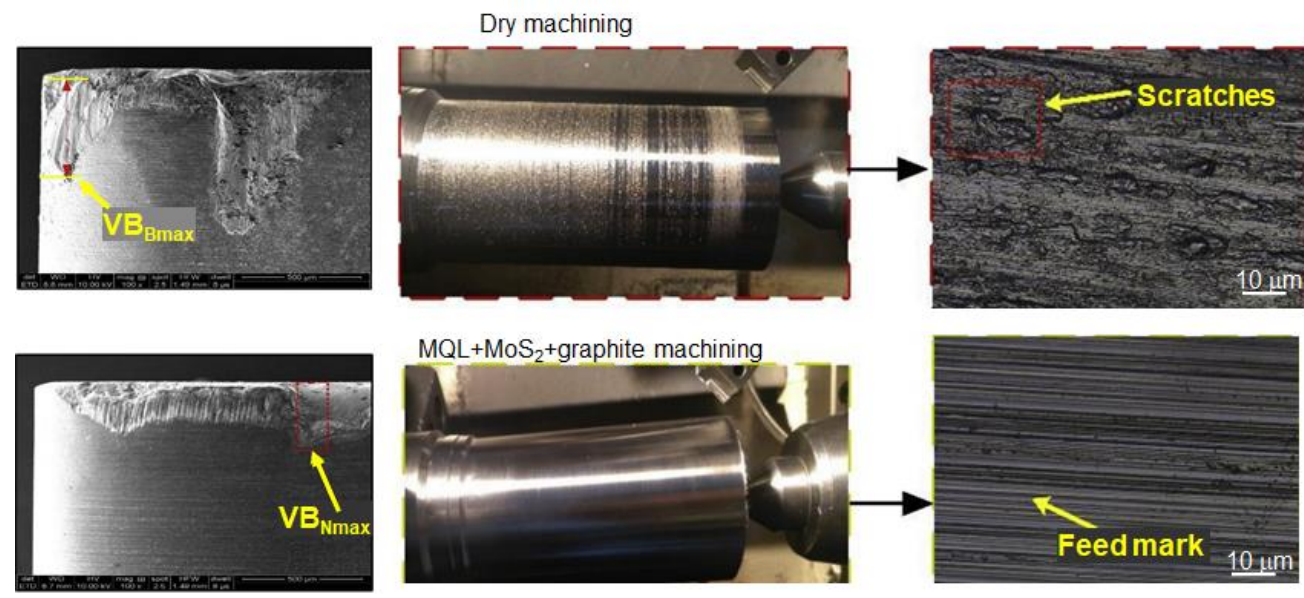

Fig. 12. SEM view of flank face surface and roughness under dry and MQL cooling at $v_{c}=350 \mathrm{~m} / \mathrm{min}, a_{p}=0.3 \mathrm{~mm}$, $f=0.1 \mathrm{~mm} / \mathrm{rev}[28]$ 
MQL vegetable oil enriched with PTFE (Teflon) particles and an aqueous solution with added graphite in various proportions used for turning Ti6A14V have increased both tool life and surface integrity [29] (Fig. 13).
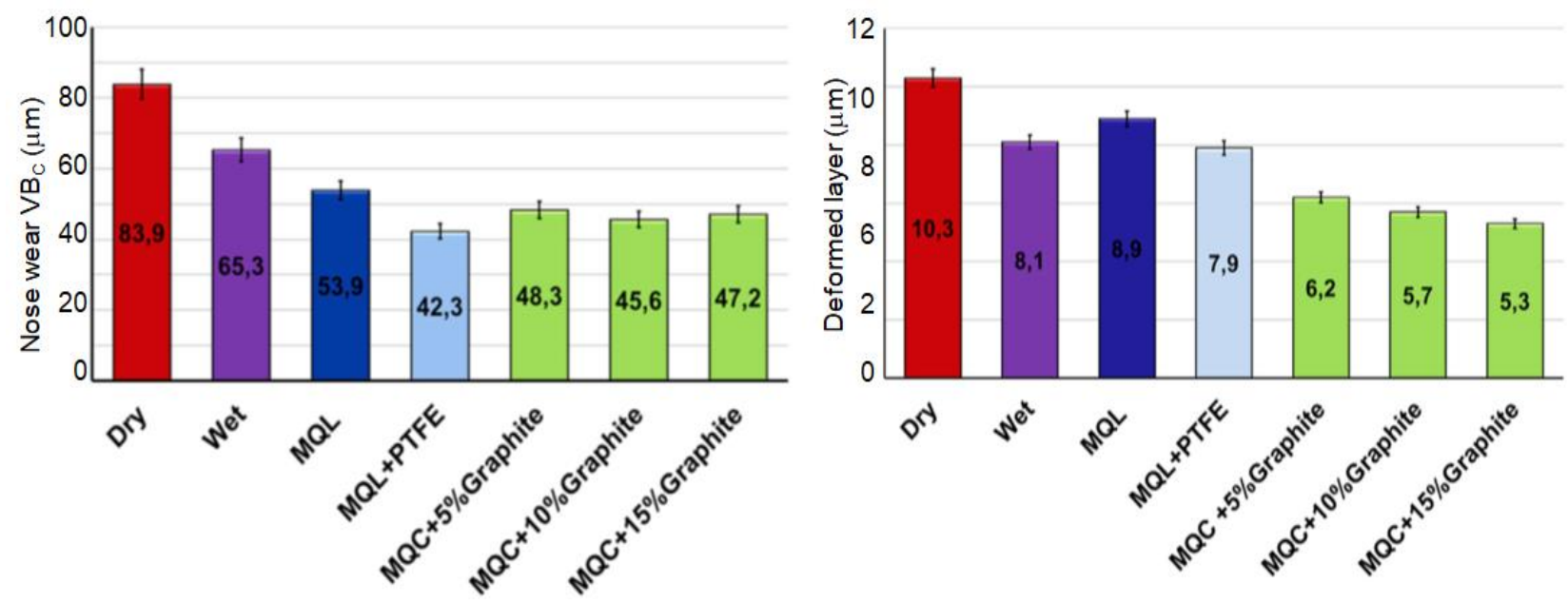

Fig. 13. Nose wear $V B_{C}$ and thickness of the deformed layer as a function of the adopted lubricating/cooling strategies [29]

Graphene is another additive used recently in nanofluids. While applying MQL based on vegetable oil with dispersed the graphene nanoparticles in TC4 milling the cutting force significantly decreases. This is likely because the graphene additive could enhance the antifriction and load-bearing capacity of the oil film formed in the milling zone. The vibration intensity of the milling process is also significantly reduced: the graphene additive enhances the damping effect of the oil film formed in the milling zone. Temperature is significantly reduced as well because the graphene additive enhances the cooling capacity of the oil film formed in milling. This results in smaller tool wear and higher tool life in the graphene MQL condition in comparison with among the four cooling/lubrication conditions. The surface integrity it was also significantly improved. Overall, the graphene additive is effective for improving the machining performances by improving the cooling and lubrication characteristics of the vegetable oil-based cutting fluid [30].

Results of application of graphene nanoplatelets of two sizes $(5 \mu \mathrm{m}$ and $15 \mu \mathrm{m})$ used as additives in a vegetable oil in turning of the Inconel 718 showed that the lowest size of nanoplatelets promoted the best surface quality and promoted the formation of a thicker severe plastic deformed layer compared to the flood case [31]. Similar results were presented in [32] where the introduction of $5 \mu \mathrm{m}$ size graphene nanoplatelets into the vegetable oil contributed to increase the nanofluid specific heat capacity without increasing its viscosity and the best surface roughness thanks to its improved efficiency as metalworking fluid. On the contrary, the opposite results were achieved when adding $15 \mu \mathrm{m}$ size particles not improving the surface finish compared to the pure MQL, which also worsened it compared to the conventional flood condition (Fig. 14). These findings prove that the nanoparticles efficiency as additives in a metalworking fluid depends on their size, which, in turn, influences their thermo-physical characteristics. 

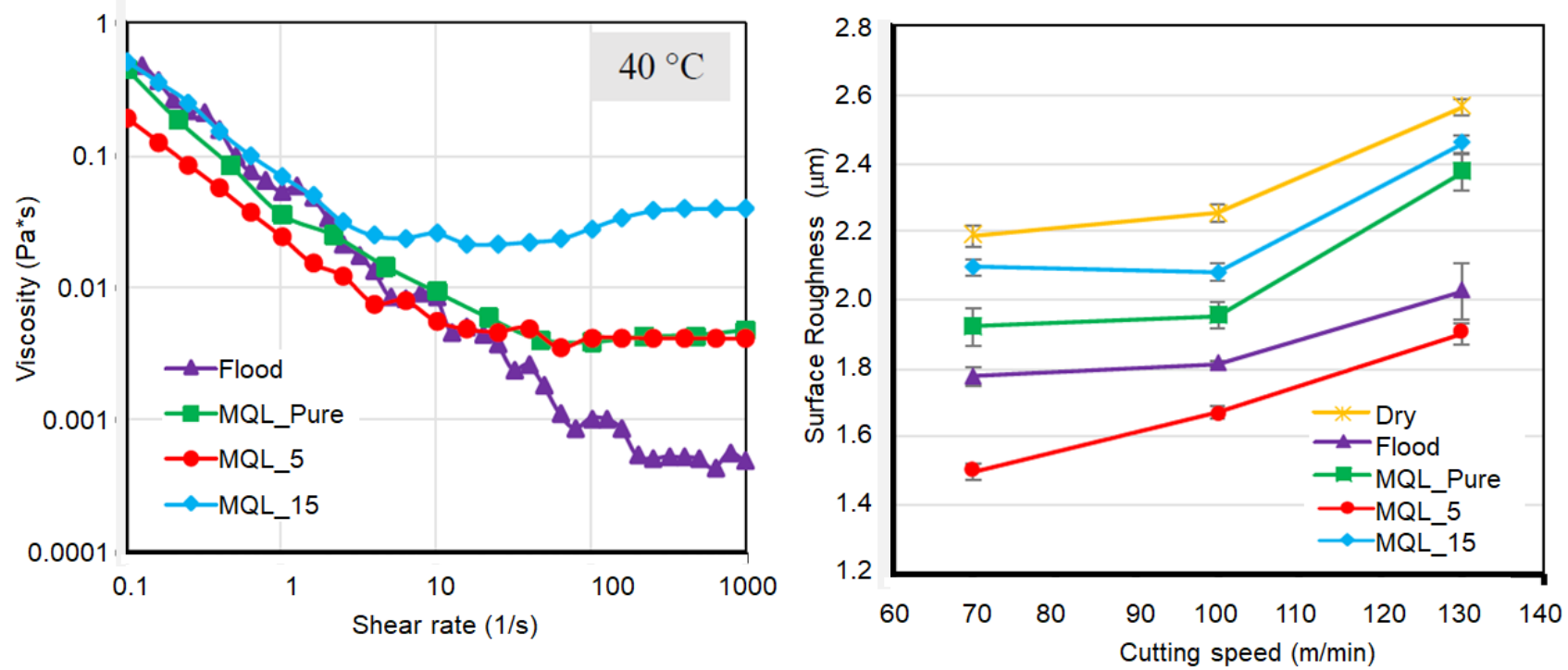

Fig. 14. Dynamic viscosity of the investigated cutting fluids at $40^{\circ} \mathrm{C}$ as a function of the shear rate and surface roughness as a function of the cutting speed and lubricating-cooling conditions [32]

Application of graphene oxide (GO) nanofluids in turning Ti6Al4V results in much lower surface roughness, less scratch and plastic deformations and lower cutting temperature than conventional coolant [33]. Main cutting force and surface roughness decreased with the increase of the concentration of graphene oxide nanosheets in the cooling fluid [34] (Fig. 15).
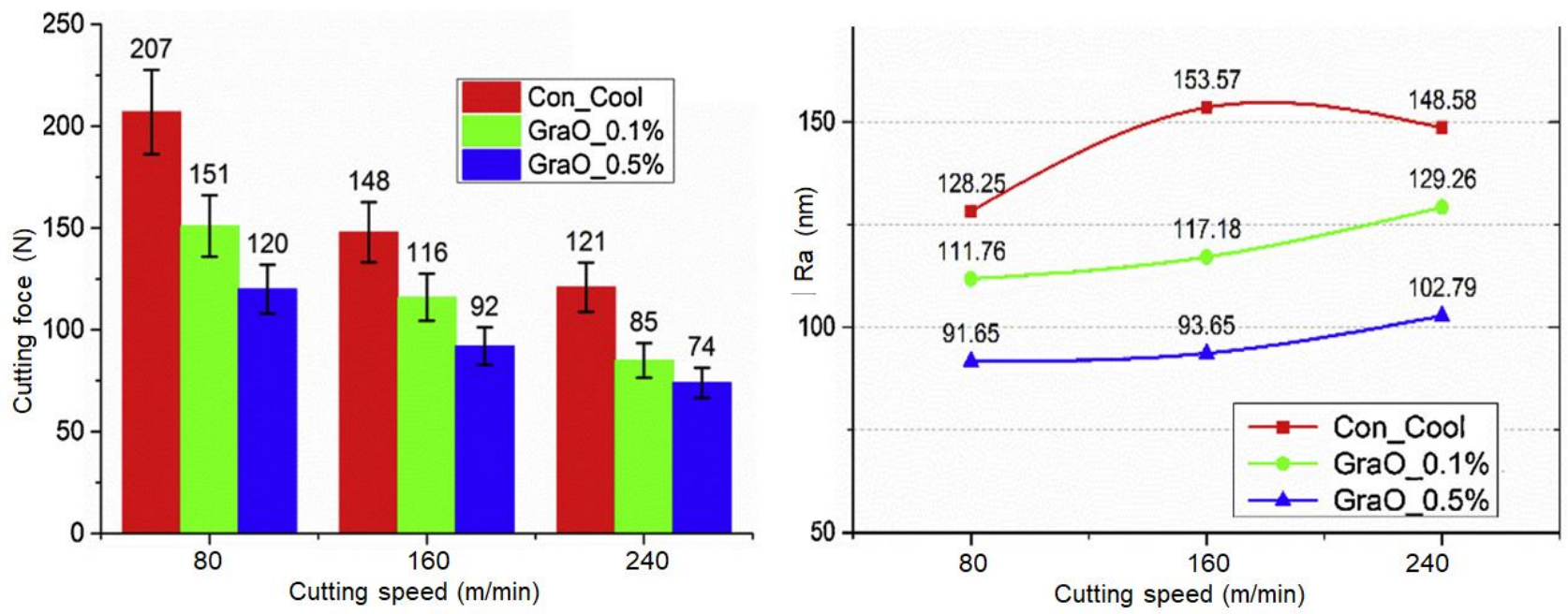

Fig. 15. Cutting forces and roughness of machined surface under 1-bar coolant pressure for conventional coolant and MQL with graphene oxide nanosheets of $0.1 \%$ and $0.5 \%$ weight percentages [34]

Another way to improve MQL effectiveness in the machining of aerospace materials is introduction of innovative medium supply. One of them is a new MQL delivery nozzle that mixes two fluids into a jet in high speed milling Ti6Al4V [35]. Vegetable oil and tungsten disulfide $\left(\mathrm{WS}_{2}\right)$ suspension are mixed in an additively manufactured nozzle and delivered through pressurized air as a coolant/lubricant spray Fig. 16. The new system achieves 
a cooling heat transfer near to $700 \mathrm{~W} / \mathrm{m}^{2} \mathrm{~K}$ at optimum set up and an increase in tool life of $\sim 1.5 \times$ compared to the next best MQL delivery system and between $3 \times$ and $11 \times$ compared to air or flood cooling (Fig. 16 e-f).
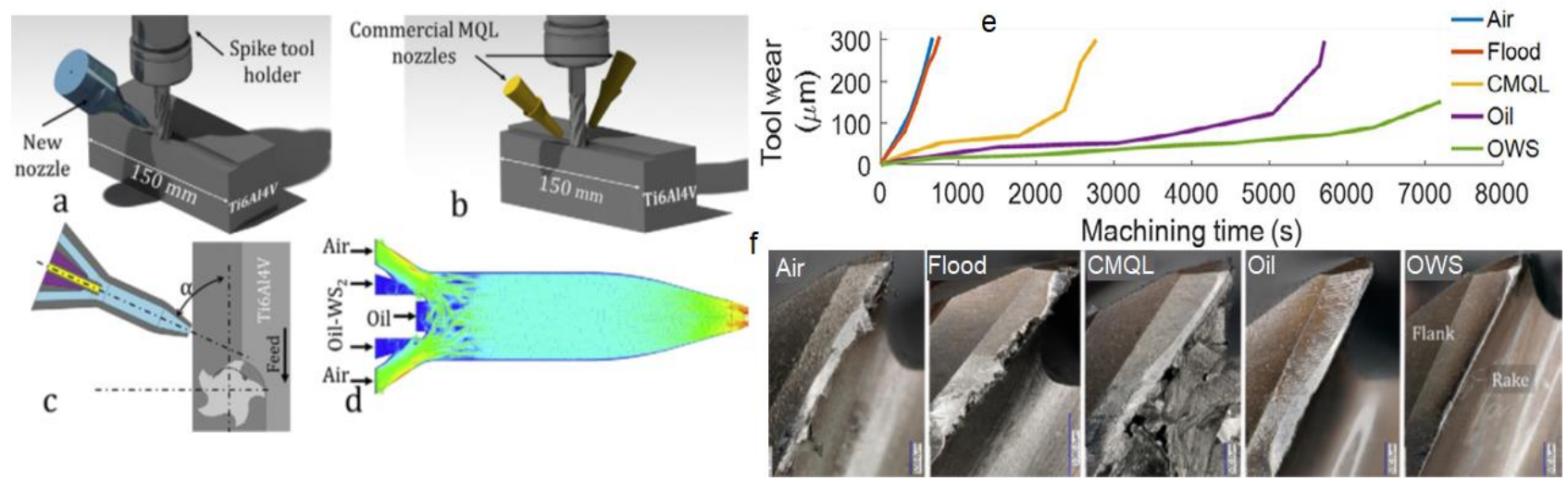

Fig. 16. Experimental setup, with (a) the new and (b) commercial nozzles; (c) the nozzle orientation,

(d) detail of the new nozzle, (e) tool wear at a cutting speed $150 \mathrm{~m} / \mathrm{min}$ and (f) end of test tool wear images after machining with various cooling: air, flood, commercial MQL, newly designed MQL nozzle spraying both rapeseed oil alone (Oil) and a $\mathrm{WS}_{2}-$ rapeseed oil suspension (OWS) [35]

Use of electrohydrodynamic atomization (EHDA) and a three-electrode setup for generating lubricant droplets in machining Ti6Al4V extended the tool life by 6 and 22 times when compared with MQL and flood cooling, respectively (Fig. 17). The improved performance is attributed to enhanced heat removal due to fine droplets generated by EHDA, resulting in reduced tool-wear growth rate [36].
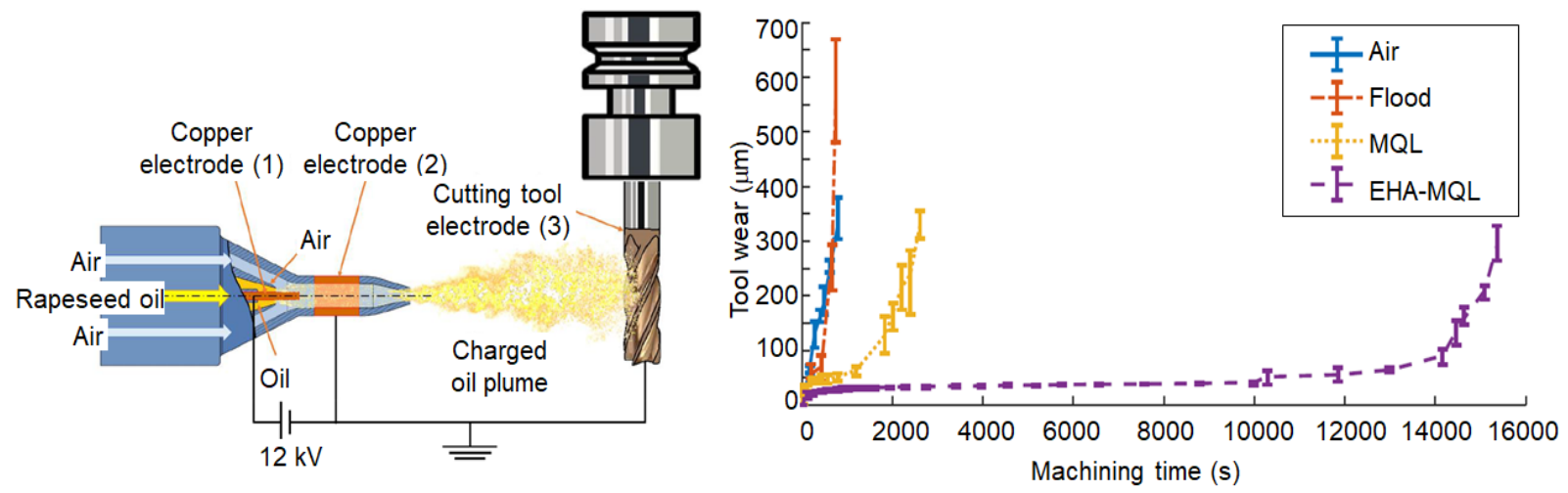

Fig. 17. Schematic of Electrohydrodynamic Atomization Minimum Quantity Lubrication (EHDA-MQL) nozzle and machining setup and tool-wear against machining time for various cooling-lubrication systems [36]

\subsection{CRYOGENIC MQL COOLING - CRYOMQL}

The literature review has shown that whilst cryogenic cooling during machining can enhance machinability of difficult-to-cut materials, the process suffers from a lack of lubrication at the cutting zone. Recently it has been reported that the combination of cryogenic and 
MQL (CryoMQL) machining improves the machining performance of aerospace materials. This cooling/lubricating strategy was built on the fact that MQL nozzle system sprays oil directly to the cutting interfaces to provide the lubrication that is essential to reduce the friction between the tool rake and chips at the secondary deformation zone and between the tool flank and the workpiece at the tertiary deformation zone. The cryogenic nozzles are mainly directed towards the cutting tool to reduce the tool temperature below the softening temperature of the tool material [37].
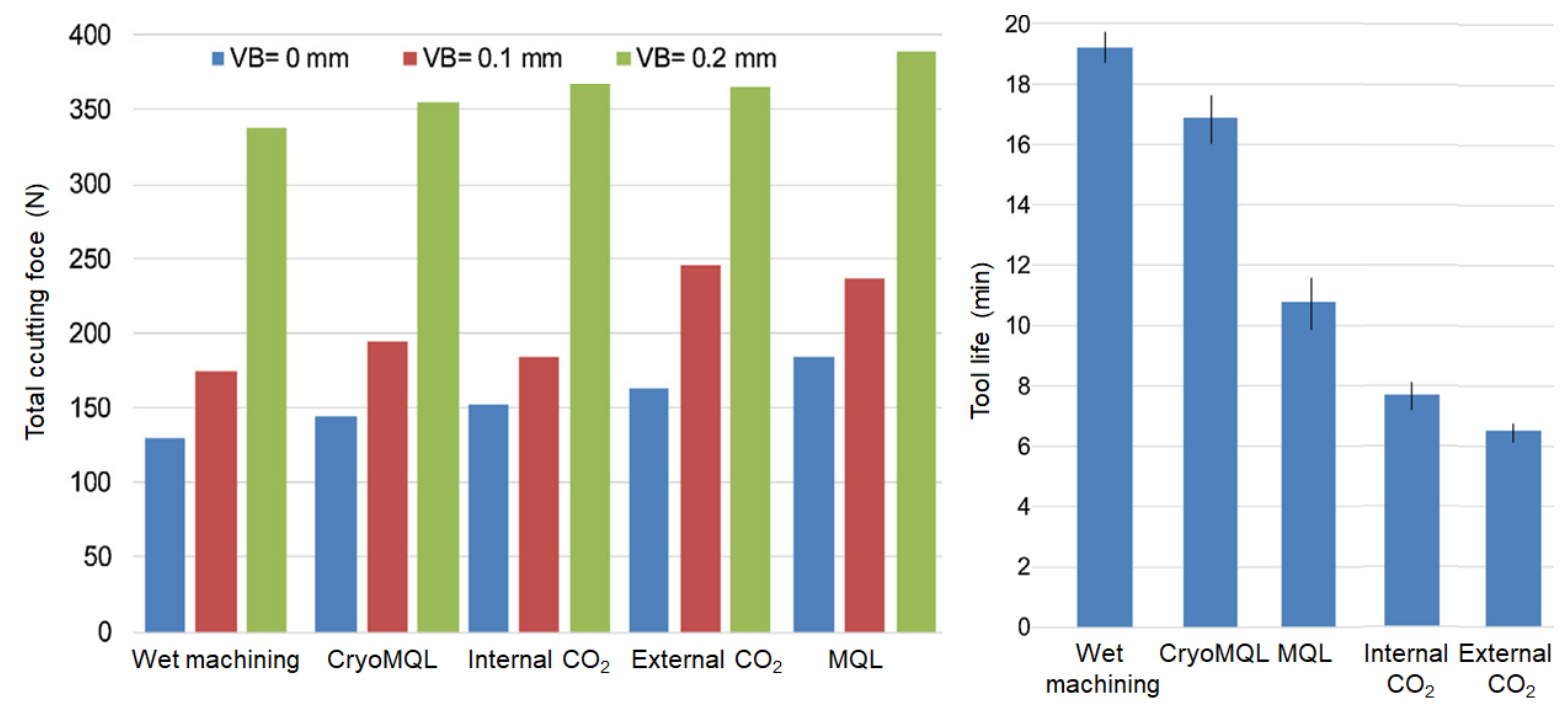

Fig. 18. Total cutting force evolution and tool life for the different cooling techniques at different wear stages [38]

External MQL lubrication working along with $\mathrm{CO}_{2}$ as internal coolant for milling Inconel 718 was compared with other cooling techniques [38]. Longest tool life was reached with wet machining, but this technique should be avoided from industrial environments in a medium term. $\mathrm{CO}_{2}$ cryogenic cooling as well as MQL lubrication working on their own, are not enough to be applied in HRSA due to machined length rates were insufficient to substitute wet machining technology. CryoMQL is the best alternative to be applied (see Fig. 18). Also, in the machining of Inconel 625 CryoMQL $\left(\mathrm{MQL}+\mathrm{LN}_{2}\right.$ ) cooling appeared to be superior to cryogenic or MQL applied alone [39] (Fig. 19).

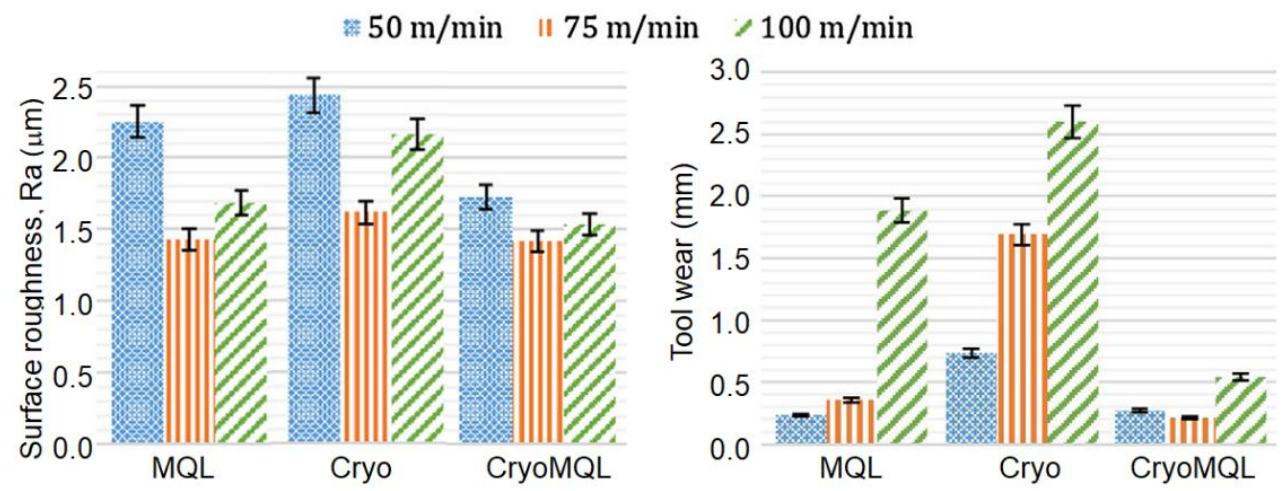

Fig. 19. The effect of cooling regimes and cutting speed on surface roughness and tool wear [39] 
Computational Fluid Dynamics modelling of the flow characteristics of the $\mathrm{LN}_{2}$ and MQL jets showed that the cooling strategy that produces the most cooling effect is to inject $\mathrm{LN}_{2}$ on the flank face and MQL on the rake face [40]. The interaction between the two jets forces $\mathrm{LN}_{2}$ with high volume fraction to stay in the gap between the flank face and the machined surface. Experimental evaluation in machining Ti6Al4V confirmed the superior performance of this CryoMQL cooling strategy in terms of tool wear and surface integrity in comparison with a flood, cryogenic and high-pressure (HPC) cooling [37, 40] (Fig. 20).
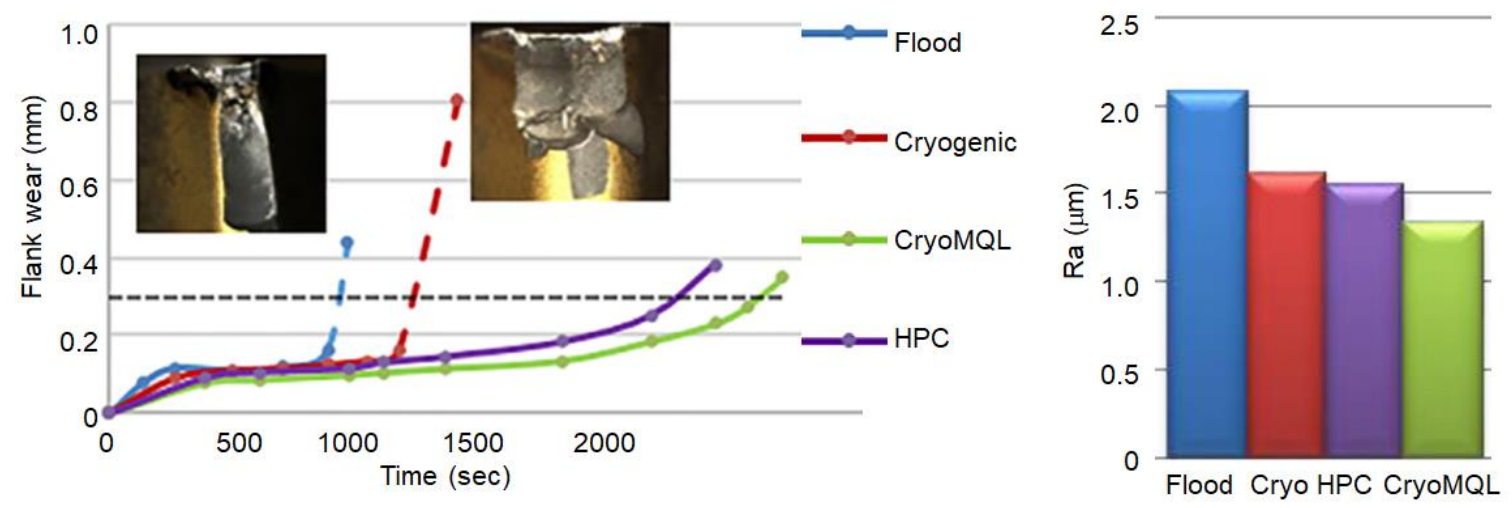

Fig. 20. Tool wear curve and surface roughness for the tested cooling methods [40]

The combination of minimum quantity carbon dioxide and oil (CMQL) supplied from the rake face were proposed to improve effectiveness of the CryoMQL lubrication in which MQL was supplied from rake face and $\mathrm{CO}_{2}$ was supplied from flank face [41]. CMQL increased tool life up to $60 \%$ and $30 \%$ during Ti6Al4V and Inconel 718 turning respectively (Fig. 21), along with enhanced surface quality in comparison to the CryoMQL supply method. CMQL has also highest reduction of tool-chip contact length due to better generated surface and smoother chip backside and higher heat removal efficiency with compare to other methods.

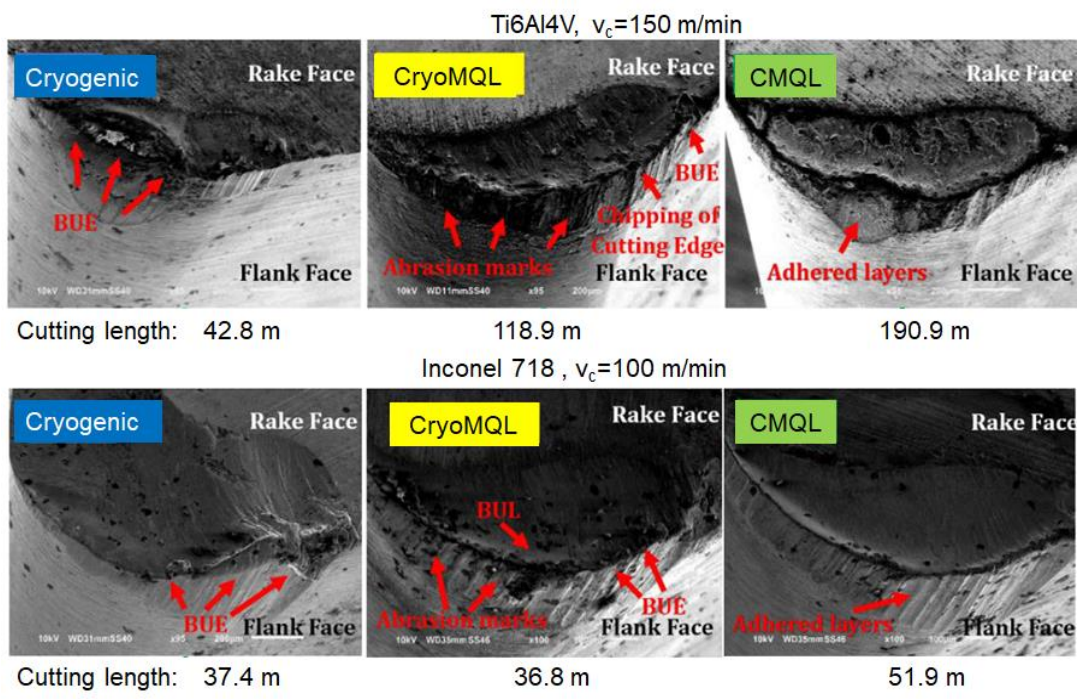

Fig. 21. Tool condition at the end of tool life for different cooling strategies after Ti6AlV and Inconel 718 turning [41] 
Although LN2 cooling has been implemented for machining titanium alloys, the effect of very low coolant temperature (down to $-150^{\circ} \mathrm{C}$ ) on the surface of the workpiece will result in workpiece hardening, thus increasing the cutting forces. The solution can be the use of indirect cryogenic cooling. A specially designed tool set was proposed that allows liquid nitrogen to be supplied to the cutting tool internally, only to cool down the tool without to be exposed to the workpiece [42]. Fig. 22 presents indirect cryogenic tool and comparison of cutting force values for various lubrication strategies over number of cutting passes. Comparing with the flood coolant strategy, nano-MQL, nano-MQL with internal cryogenic cooling and nano-MQL with indirect cryogenic cooling consumed less cutting force by $7 \%$, $4 \%$ and $54 \%$, respectively. However, catastrophic failure occurred in the external cryogenic in the 10th pass and tool failure was reported due to strong adhesion in the internal cryogenic in 8th pass. As a result, the proposed indirect cooling along with nano-MQL lubrication strategy provides an excellent solution to the problem of excessive workpiece hardening. The cutting force is significantly reduced and helps in maintaining a smooth cutting process. Due to the additional lubrication, the cutting chips that are trapped on the tool helix have been removed, hence low cutting force is used during the process.

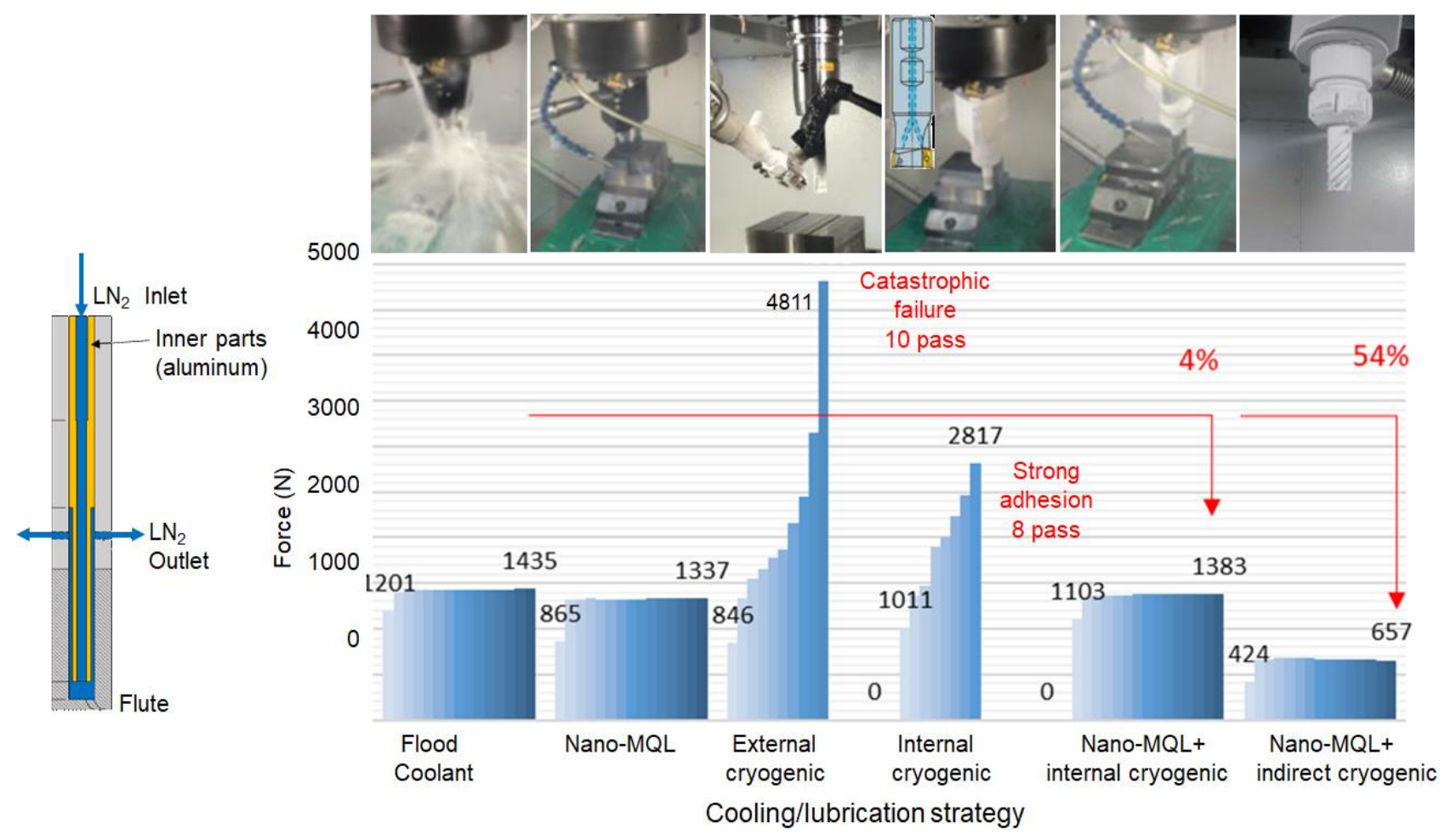

Fig. 22. Custom designed of indirect cryogenic tool (right) and cutting force values for various lubrication strategies over number of cutting passes [42]

PCD tools are not commonly used in the HSM of Ti alloys because of the problem of thermally induced chemical wear. It was found however that with the use of cryogenic $\mathrm{LN}_{2}$ cooling, the tribological system changed sufficiently to allow for sustained machining performance, with very low tool-wear $\left(V B<10 \mu \mathrm{m}\right.$ after $65 \mathrm{~min}$ of cutting at $\left.v_{c}=240 \mathrm{~m} / \mathrm{min}\right)$ 
[42]. Surface roughness values were as low as $\mathrm{Ra}=40 \mathrm{~nm}$ for cryogenic machining of Ti6Al4V. Interestingly, flood machining did not lead to reduce surface roughness values. However, CryoMQL ( $\mathrm{LN}_{2}$ and oil based MQL) cooling did yield the lowest cutting forces compared to both flood and cryogenic conditions. All conditions evaluated during this study resulted in cutting forces of less than $15 \mathrm{~N}$, suggesting that cryogenic precision machining with PCD tools may be a suitable alternative to grinding, even for slender and thin-walled components.

\subsection{HIGH-PRESSURE COOLING}

Among the available cooling/lubricating techniques, high-pressure jet-assisted machining offer opportunities in terms of increasing the productivity, reducing temperature in the cutting zone, excellent chip-breaking ability, and reduction of the costs associated with cooling/lubrication fluids [44].

A high-pressure coolant (HPC) supply with its cooling and lubrication ability was found to be very helpful for decreasing the coefficient of friction and temperature during machining of Ti-5553, consequently lowering progression of wear and cutting force components Fig. 23. The greatest tool life is achieved by high-pressure coolant supply, and cryogenic cooling achieves the second greatest tool life. MQL is inefficient for improving the machining performance of this alloy $[45,46]$.
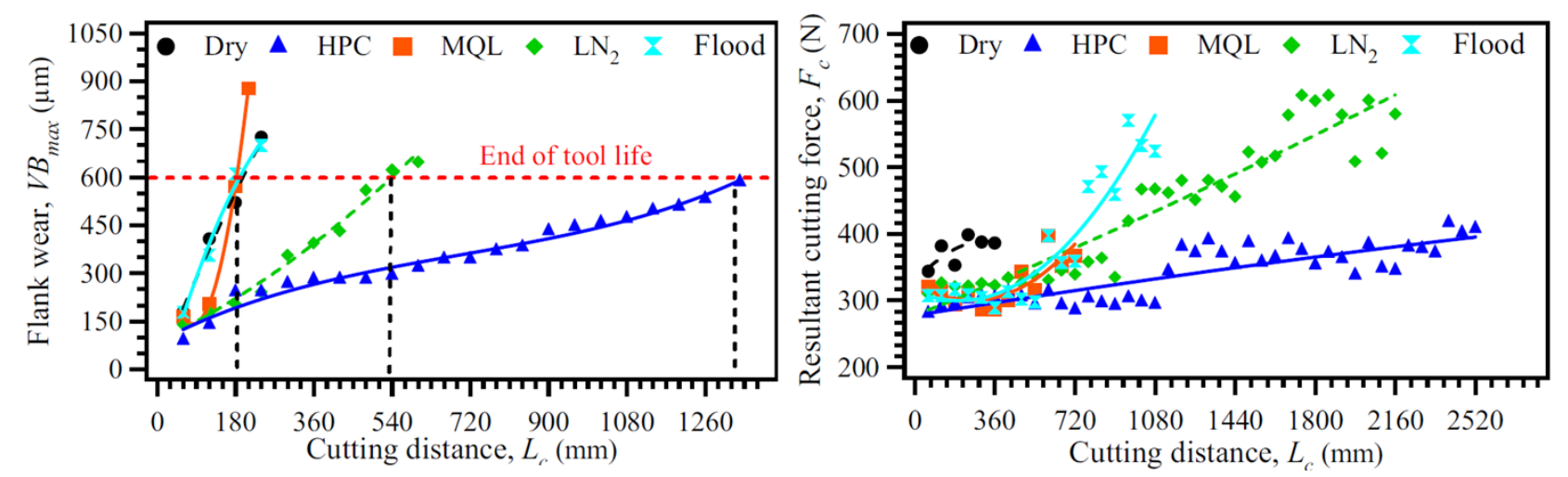

Fig. 23. Tool wear rate and surface roughness of the parts machined under various machining conditions [46]

An attempt to use HPC in machining of Inconel 625 with SiAlON-based ceramic tools has shown that it does not increase or reduce the tool life compared to conventional cooling. The tool wear was characterized by flank wear and edge chipping. The notch wear was not significant. Nevertheless, the high-pressure cooling contributed to excellent chip breaking [47]. The diameter of the nozzle, the pressure of the jet, and diameter of the nozzle are the most important factors as far as cutting tool temperature is concerned. Major reduction in chip size can be achieved by increasing the pressure of the jet [44].

The results of HPC application in turning of nickel-base superalloy Haynes 282 in solution annealing Large Grain Solution (LGS) state and precipitation hardened Large Grain Aged (LGA) revealed that although it caused cutting forces decrease it does not show 
correlation with flank and notch wear decreasing (Fig. 24). Therefore, HPC is not recommendable for this material [48].
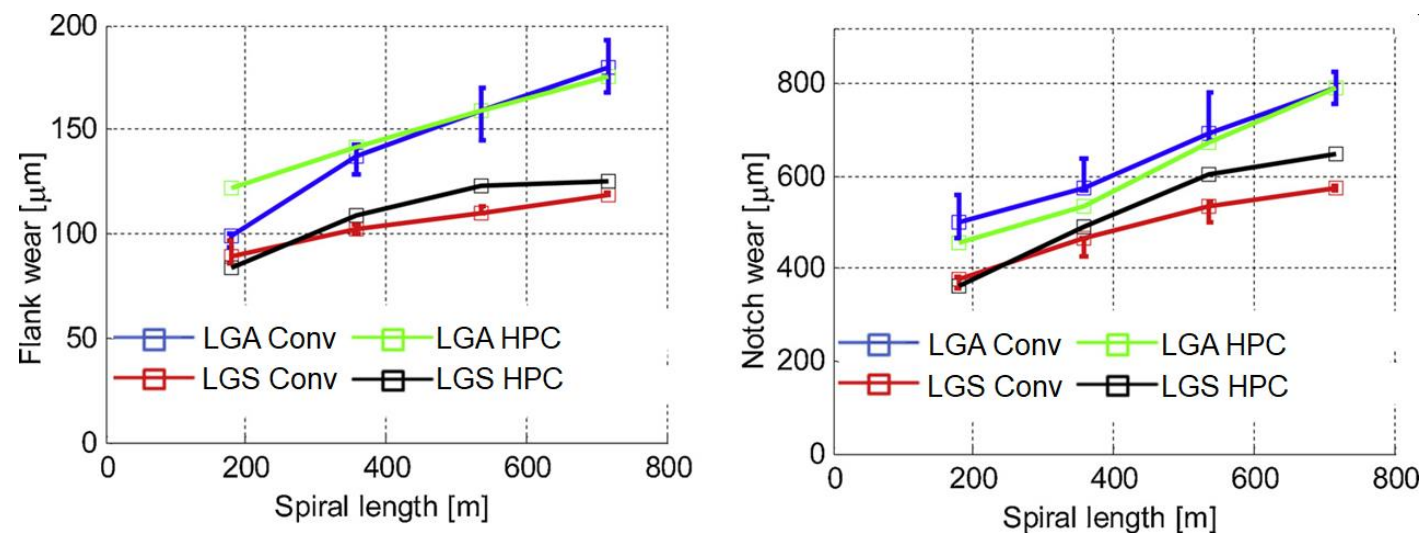

Fig. 24. Mean flank wear and mean notch wear on facing tests Haynes 282 alloy with conventional cooling and high-pressure cooling [48]

\section{HYBRID CUTTING PROCESSES}

Hybrid manufacturing processes are based on the simultaneous and controlled interaction of process mechanisms and/or energy sources/tools having a significant effect on the process performance [1]. Here recent developments of Vibration Assisted Machining, Ultrasonic Assisted High-Performance Cooling and Laser Assisted Machining application in machining of aerospace materials are presented.

\subsection{VIBRATION ASSISTED MACHINING VAM}

Vibration-assisted machining (VAM) is a process in which high-frequency small amplitude vibration is applied to the tool or workpiece to improve cutting performance. This generates oscillations of the cutting edge in the range of a few micrometers, thereby causing a high-frequency change in the cutting speed and/or the feed. Consequently, a reduction of cutting forces, an increase of the tool life, and an improvement of the workpiece quality can be achieved. It has been applied to several machining processes including drilling, turning, grinding, milling and more recently for the processing of hard-to-machine materials. State-of-the-art on the principle and structural design of VAM systems are reviewed in [3]. The complex tool tip trajectories in vibration-assisted milling can result in a rough surface, which affects the cutting process. It may be noted that the current vibration-assisted tool path overlaps in some regions with the surface contour left by the previous cutting path(s), so in these overlapping regions the cutting tool edge may break contact with the workpiece and discontinuous chips are produced. Since some of the material in the current cutting path has been removed by previous cuts, periodic separation of the tool from the workpiece may occur (Fig. 25). 


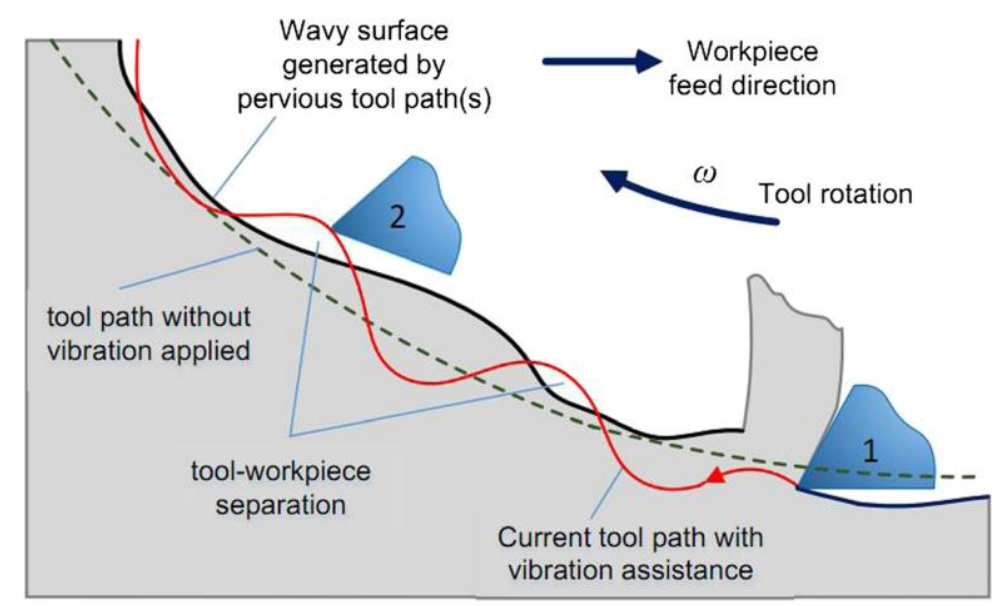

Fig. 25. Tool-workpiece separation during vibration assisted milling process [3]

The history and current status of the vibration devices, including the design theory and principles are presented in [49]. In recent years, several articles have been devoted to the VAM application in machining of Ti6Al4V.

Comprehensive experimental investigation of the effects of longitudinal (LVAM) and longitudinal-torsional (LTVAM) vibrations on the cutting force, the tool life, and the surface quality when milling Ti-6Al-4V was presented in [50]. LTVAM showed better overall process performance than the pure longitudinal vibration. Cutting forces decrease $44.3 \%$ in LVAM, and 57\% in LTVAM an average maximum as the torsional vibration component leads to a lower contact time between the tool and the workpiece (Fig. 26).
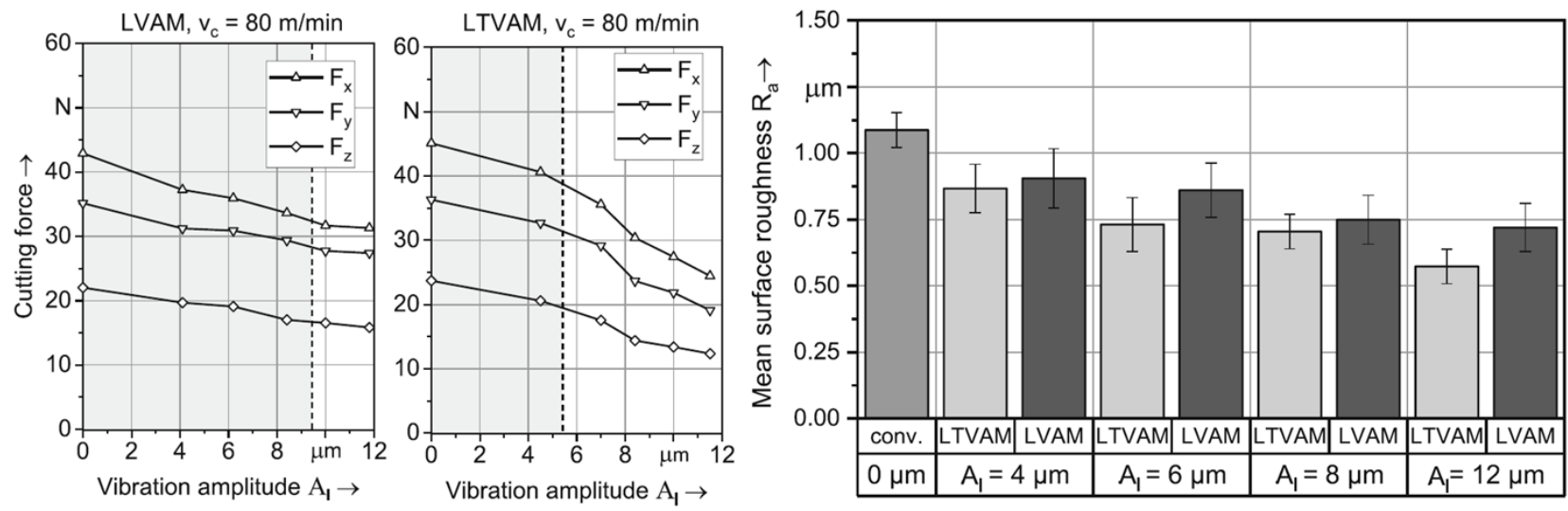

Fig. 26. Cutting forces and surface roughness for peripheral milling at different vibration amplitudes for LVAM and LTVAM [50]

The bottom surface roughness of the slot-milled specimens decreases from $\mathrm{Ra}=0.9$ to $0.78 \mu \mathrm{m}$ (LVAM) and $0.75 \mu \mathrm{m}$ (LTVAM). LVAM and LTVAM can significantly increase the compressive residual stresses and the surface hardness in slot milling.

Longer tool life, lower cutting force, improved surface roughness, and lower cutting temperature in the VAM milling of Ti6Al4V as compared to that of conventional milling were also reported in [51]. 
A closer look at the micro-texture generation mechanism and the effect of textured surface characteristics on tribological properties of machined surfaces in ultrasonic VAM of Ti6Al4V showed that the separation space produced between the milling cutter and the specimen in VAM could greatly reduce accumulation of cutting heat in the cutting zone and enhanced the aerodynamic lubrication with reduced friction [52]. Moreover, the continuous change of relative velocity, relative acceleration and reversed frictional force between a tool and workpiece are also helpful to remove chips. Uniform micro-texture could significantly improve surface morphology and surface quality. A great number of tool path marks consisting of concaves, bulges and irregularities appeared on machined surfaces in conventional milling are fundamentally different from uniform micro-vibration texture produced in VAM (Fig. 27).
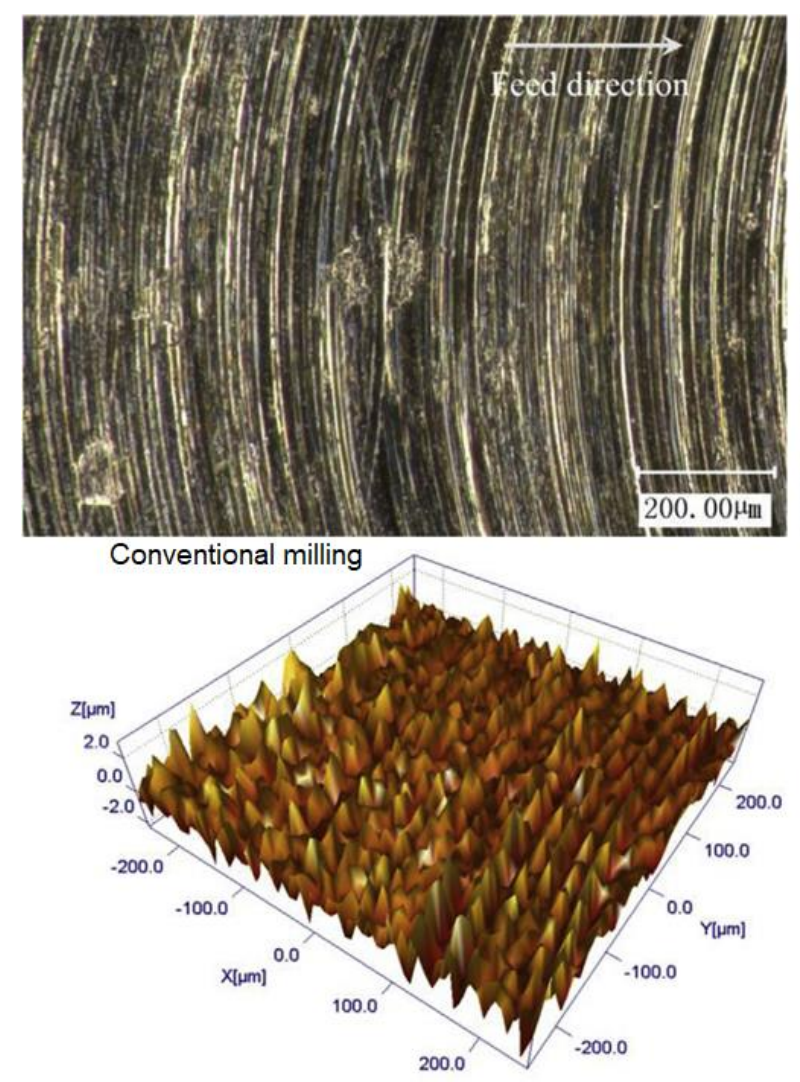
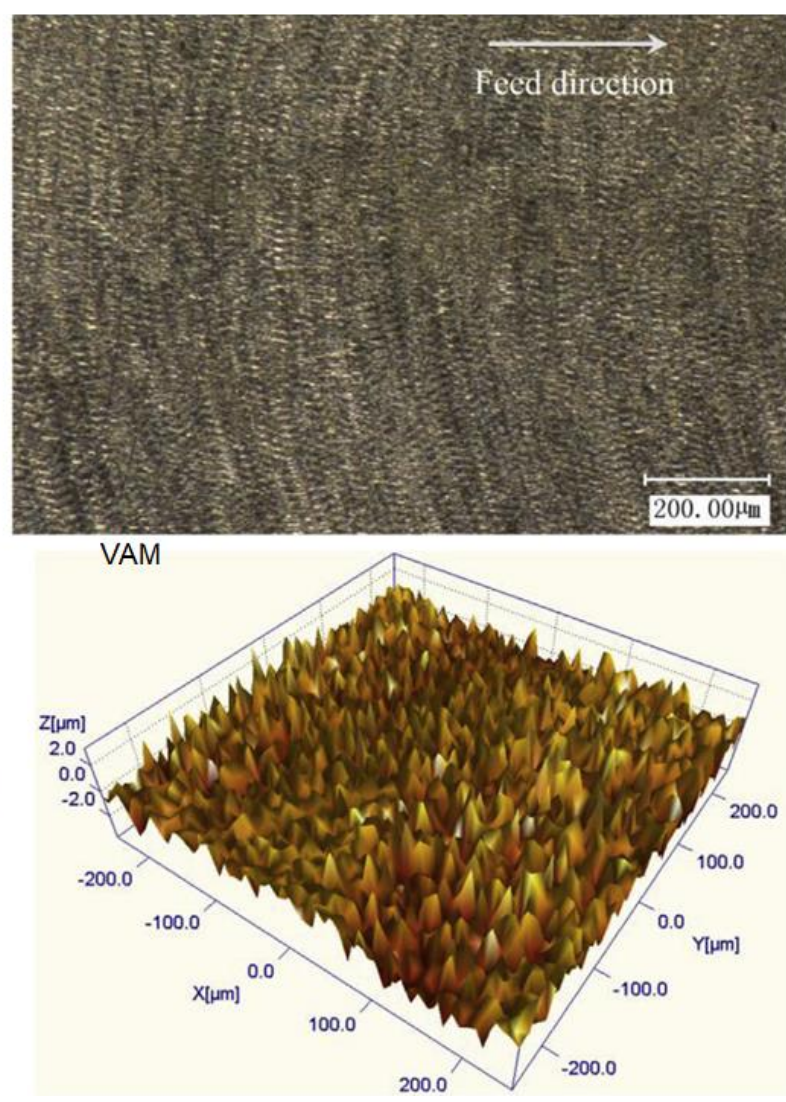

Fig. 27. Comparison of 2D/3D surface morphology between conventional milling and VAM of Ti6Al4V [52]

The chip segmentation causes stress and temperature oscillations at the tool edge, leading to fast tool wear and damage of machined surface in cutting of Ti6Al4V. Experimental observations of chip microstructure show that the shear bands disappear when vibration assistance is applied along tangential direction at certain cutting speeds [53]. The frequency of temperature and stress variations depends on the frequency of the vibration assistance. As a result, the pitch length of the chip segmentation is determined by the excitation frequency of the vibration assistance and the cutting speed rather than uncut chip thickness. 
A continuous curled chip formation with a high thermal load is a critical challenge during conventional drilling process of Ti6Al4V. In addition, adverse side effects will take place on the drilled hole quality, as well as the drill tool performance, which is not acceptable in the aerospace industry. The effect of low-frequency $(\sim 100 \mathrm{~Hz})$ vibration assisted drilling (LV-VAD) on the chip morphology and subsurface examination of the microstructure, surface, and depth profile of residual stress were examined in [54]. This method showed a significant reduction in the cutting process temperature by switching from continuous to interrupting cutting (Fig. 28). LV-VAD has improved the residual stress to compressive which has a significant impact on the part fatigue life. The resulting chip evacuation mechanism enhanced the drilled hole size error, reaching IT9 on the standard tolerance grades combined with more than $50 \%$ reduction in the hole surface roughness.
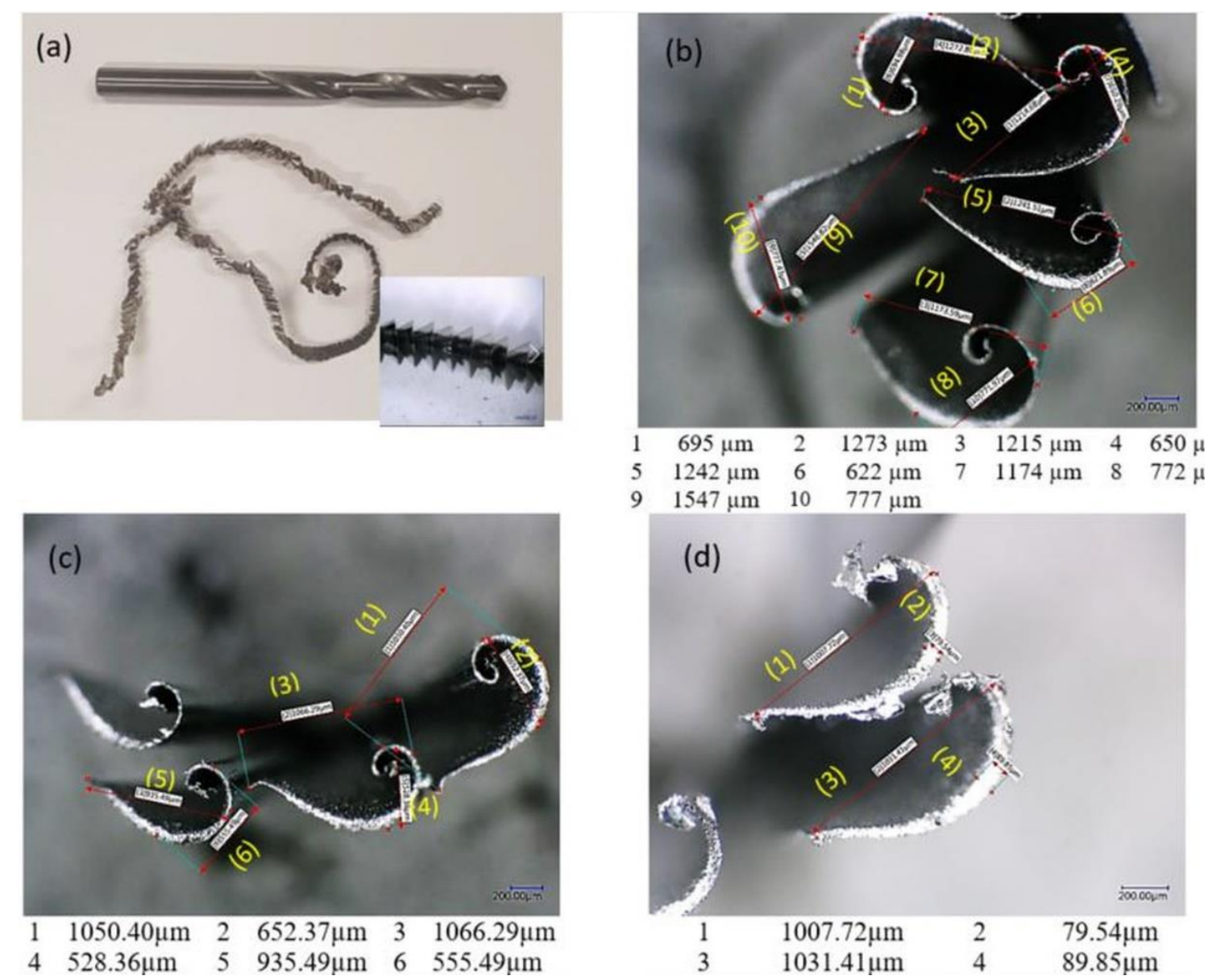

Fig. 28. Effect of the LF-VAD module amplitude $(A m)$ on the Ti6Al4V chip morphology a) conventional, b) $A m=0.07 \mathrm{~mm}$, c) $\mathrm{Am}=0.1 \mathrm{~mm}, \mathrm{~d}) A m=0.16 \mathrm{~mm}[54]$

Cyclic cracks, where gross and micro cracks are located along the shear band, are the prevailing mechanism for saw-tooth chips in LF-VAD of Ti6Al4V. The formation of these cracks showed a significant dependency on the vibrational amplitude [55]. The results showed a reduction in the chip thickness ratio and an increase in the segmentation degree when increasing the vibration amplitude (Fig. 29). 

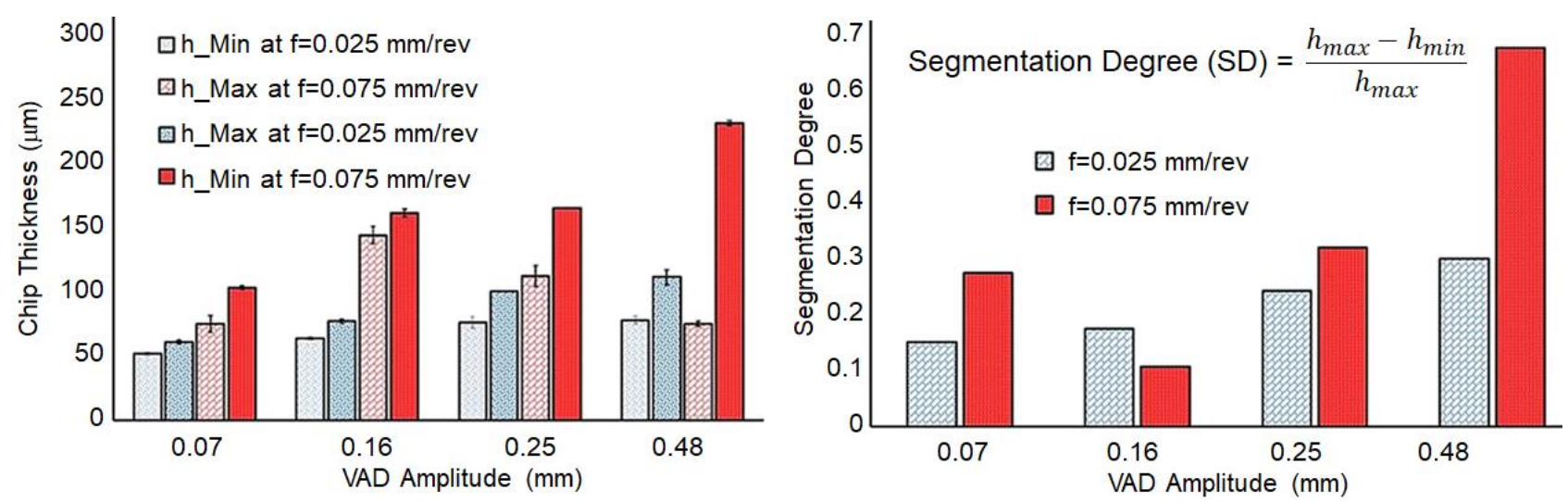

Fig. 29. Geometric characterization for LF-VAD chips cross section for $h_{\max }, h_{\min }$ and segmentation degree [55]

During LF-VAD operation for Ti6Al4V, discrete chips are produced only at certain amplitude-frequency conditions, which have been represented in the form of a characteristic U-curve, which can serve as a ready reference to select the suitable modulation conditions for interrupted chip generation [56] (see Fig. 30).

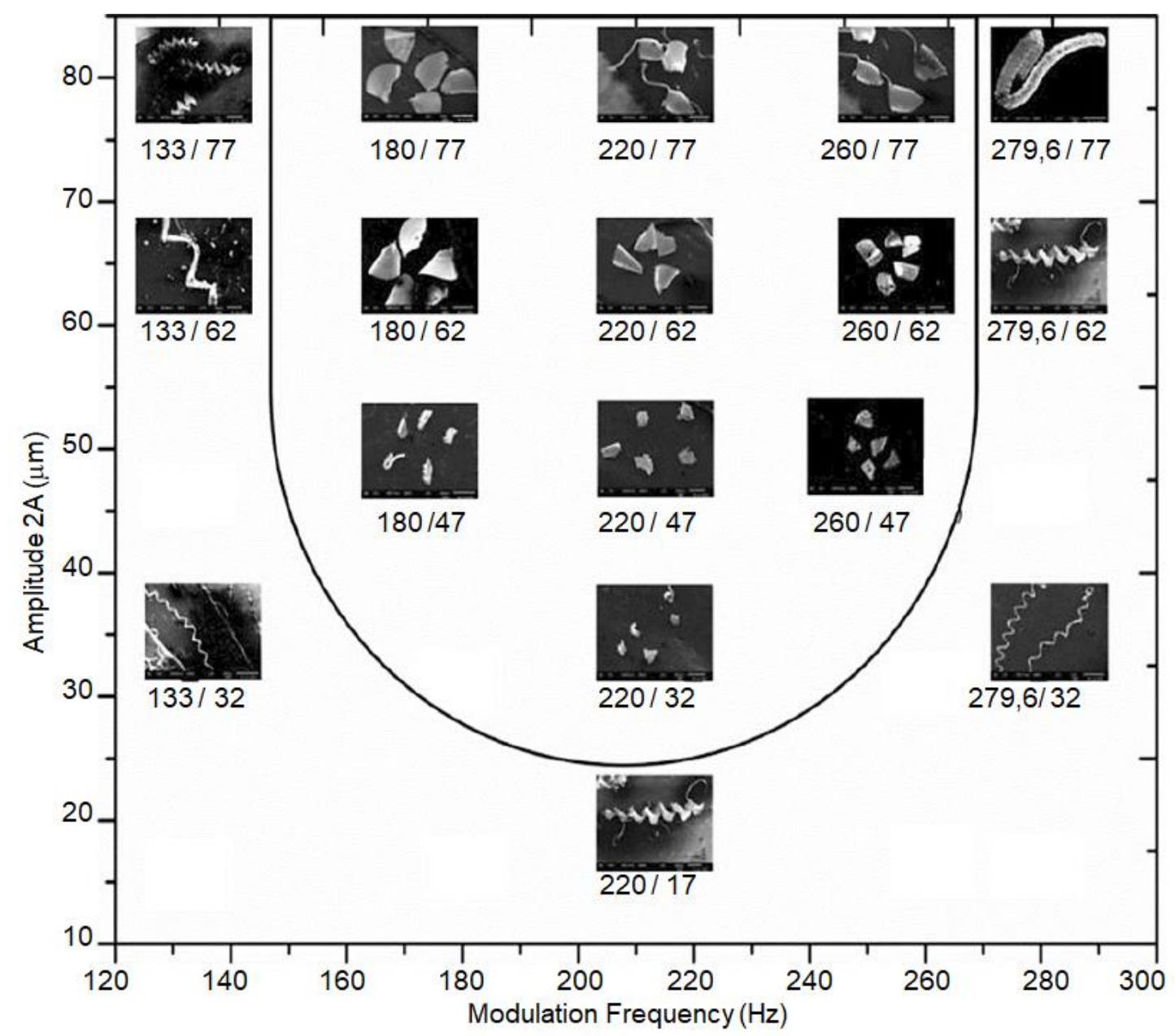

Fig. 30. Frequency-amplitude graph showing discrete chips generation region during LF-VAD of Ti6Al4V [56] 
Ultrasonic VAM used in turning of Inconel 718 and 625 also leads to significant cutting force reductions, improved surface roughness, and generates more compressive stresses when compared to those in conventional turning [57].

Regardless of the benefits of using MQL described in section 2.2, oil mist discharged from MQL system induces negative effects for working space possessing a potential health risk for machine operators. Therefore, attempts are being made to combine the advantages of ultrasonic vibration and MQL (VAM\&MQL) lubrication without making oil mist. Furthermore, given the advantages of the VAM\&MQL technology, it is expected that using them simultaneously can further improve the efficiency of titanium alloys machining.

Continuous lubrication supply to the cutting edge without making oil mist system and ultrasonic vibration (U-CMQL) was applied in turning of Ti6A14V [58]. Valve-less micropump delivers small amounts of fluid (Fig. 31). The U-CMQL technique not only maintains a neat working area, but also improves the machinability characteristics to some extent. In comparison with dry machining and ultrasonically assisted machining, U-CMQL shows lower cutting force and tool wear rate due to the combined advantages of lubrication and vibration. Moreover, short tool-chip contact length, favorable chip morphology, and better surface integrity are obtained (Fig. 31).
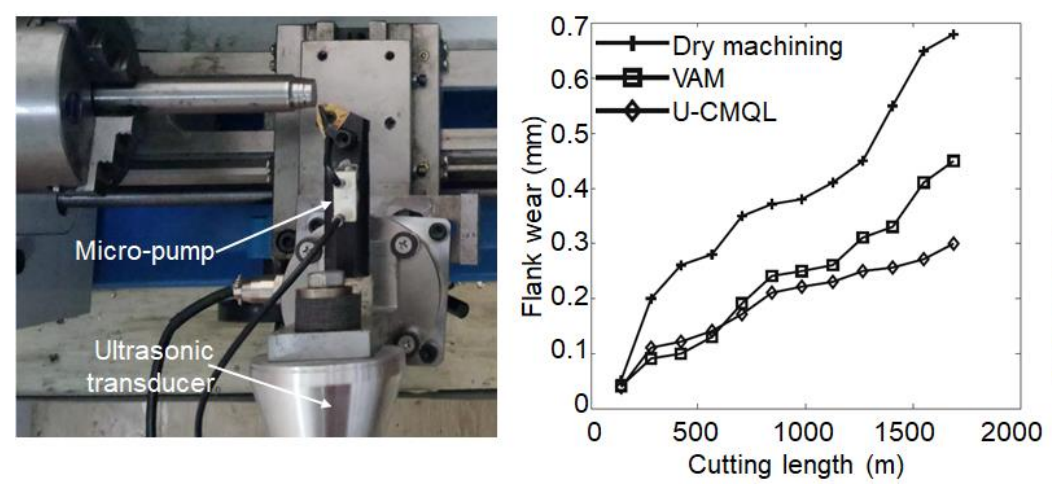

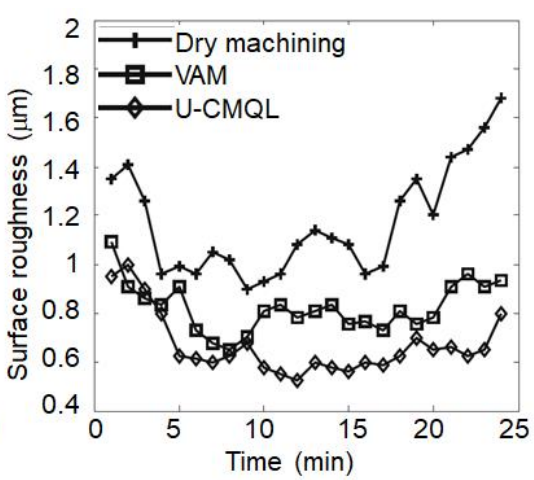

Fig. 31. Experimental setup, flank wear with cutting length and surface roughness under different cooling conditions [58]

Comparison of conventional milling (CM), feed-direction ultrasonic vibration-assisted milling (VAM) and VAM\&MQL of Ti6Al4V revealed that the tool wear in VAM was dominated by ultrasonic-frequency dynamic load. Ultrasonic-frequency cutting force, friction, vibration impact and cutting inflection points of tool-tip trajectory worked together on the cutting edges. The tool wear morphology in feed-direction VAM was mainly characterized by tool-tip fracture, impact crack, friction traces and fatigue crack. The results of machined surfaces indicated that compared with the surfaces obtained in CM and general VAM\&MQL method could significantly improve the finished surface quality, which can also improve the tool wear to a certain extent [59] (Fig. 32).

The same methodology was applied to milling of TC4 alloy [60]. Here too compared with surface roughness in CM and UVAM, the surface roughness in VAM\&MQL is improved by about 30-50\% and about 20-30\%, respectively (Fig. 33). Interestingly, due to the breakage of the enclosed area between the tool edge and workpiece the separate type cutting mechanism 
in VAM can provide convenient access for ultra-fine droplets and low temperature highpressure compressed air to effectively reach the tool workpiece interface. Cutting force in both general VAM and combined VAM\&MQL methods can be significantly reduced (Fig. 33).
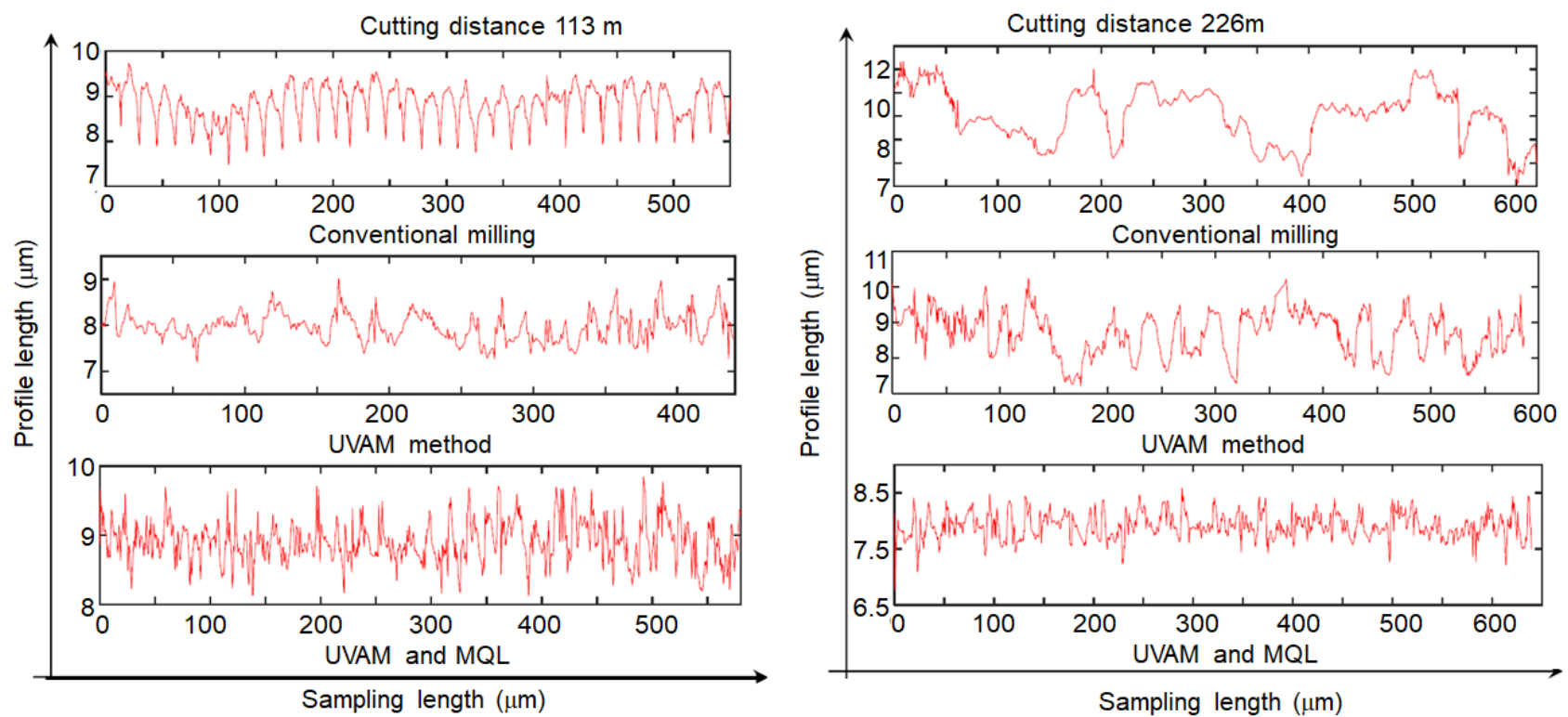

Fig. 32. Surface profile under conventional, VAM and VAM\&MQL milling of Ti6Al4V after the cutting distance of the cutter $113 \mathrm{~m}$ and $226 \mathrm{~m}$ [59]
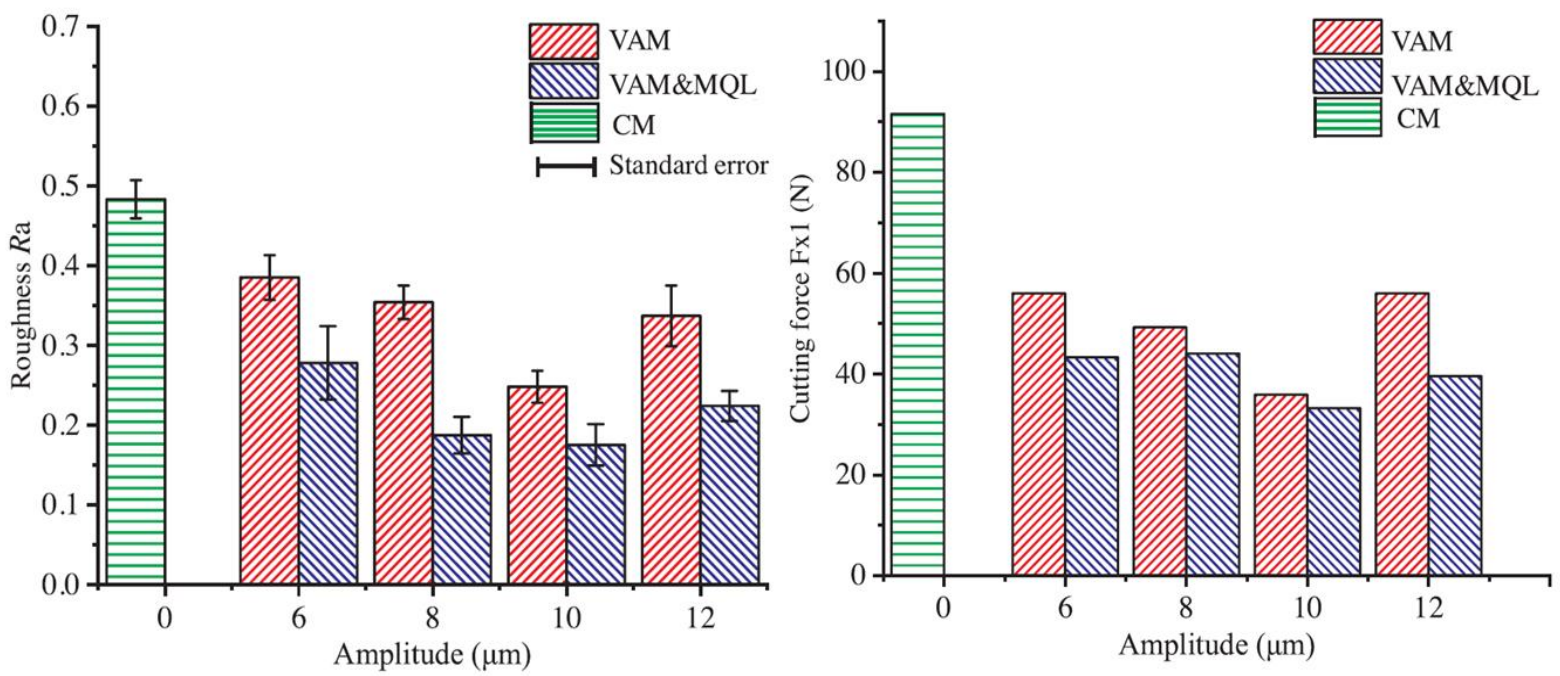

Fig. 33. Effect of vibration amplitudes on average cutting force and surface roughness under different methods of machining TC4 [60]

As mentioned above, high-pressure coolant (HPC) is widely applied in recent years for machining titanium alloy, and favorable results are achieved. As with MQL, VAM can allow high-pressure jet to fully get access to tool cutting edge. The tool life in turning of Ti6Al4V was significantly extended by HPC compared to flood cooling [61]. The effect can be 
enhanced when coolant pressure increases (Fig. 34). Combination of VAM and HPC (VAM\&HPC) can reduce principal force and feed thrust force for 15-45\% when cutting speed is among 200-400 m/min. Cutting temperature was also remarkably reduced (Fig. 34).
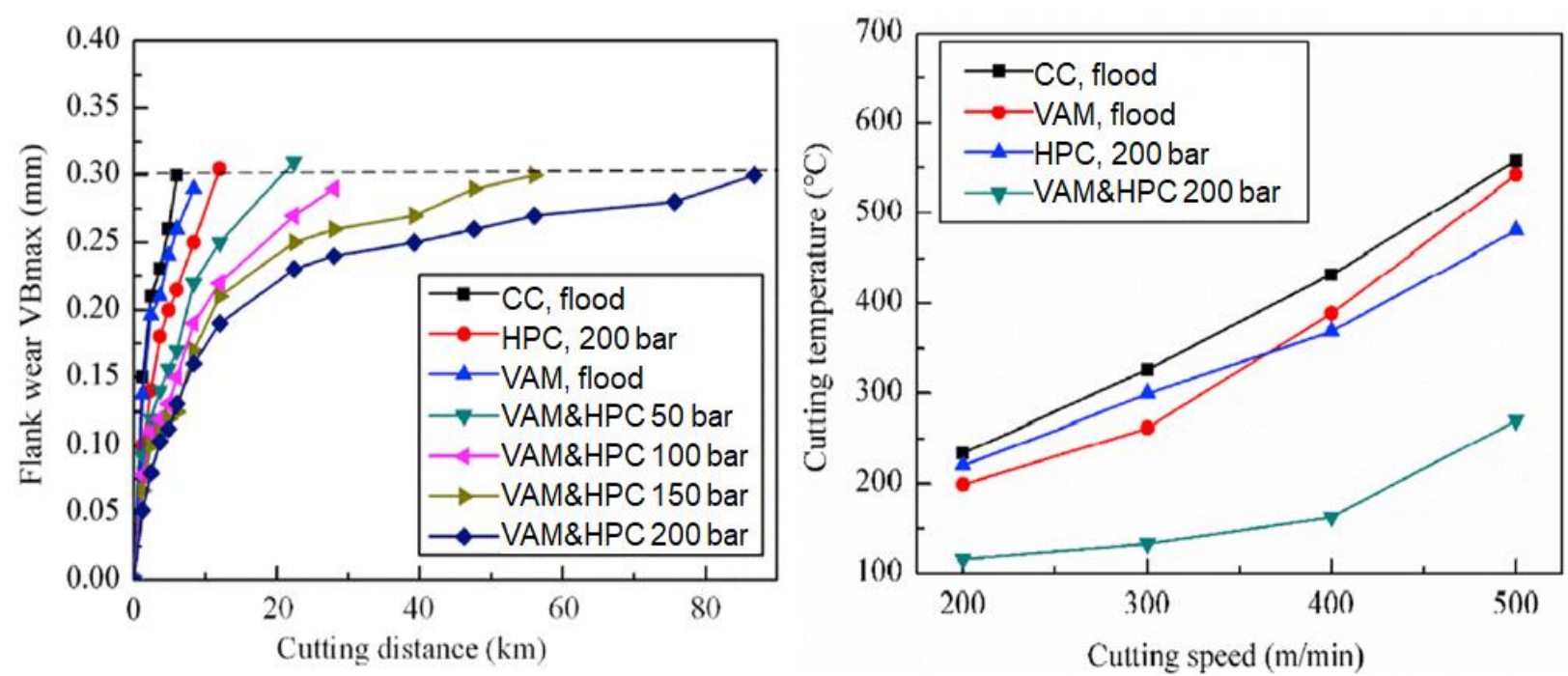

Fig. 34. The change of flank wear and cutting temperature under conventional cooling (CC), vibration assisted machining (VAM) and VAM combined with high pressure cooling (VAM\&HPC) in turning of Ti6Al4V [61]

Another VAM application that has emerged in recent years is the machining of composites and stacks. Carbon-fiber reinforced silicon carbide matrix (C/SiC) composites are typical difficult-to-cut materials due to high hardness and brittleness. The main wear mechanism of the diamond-coated milling cutter is abrasive wear, and the main wear form is the coating peeling. Compared with the traditional milling, the tool wear can be reduced by the ultrasonic vibration milling in machining process. It decreases first and then increases with the increase of ultrasonic amplitude [62] (Fig. 35).
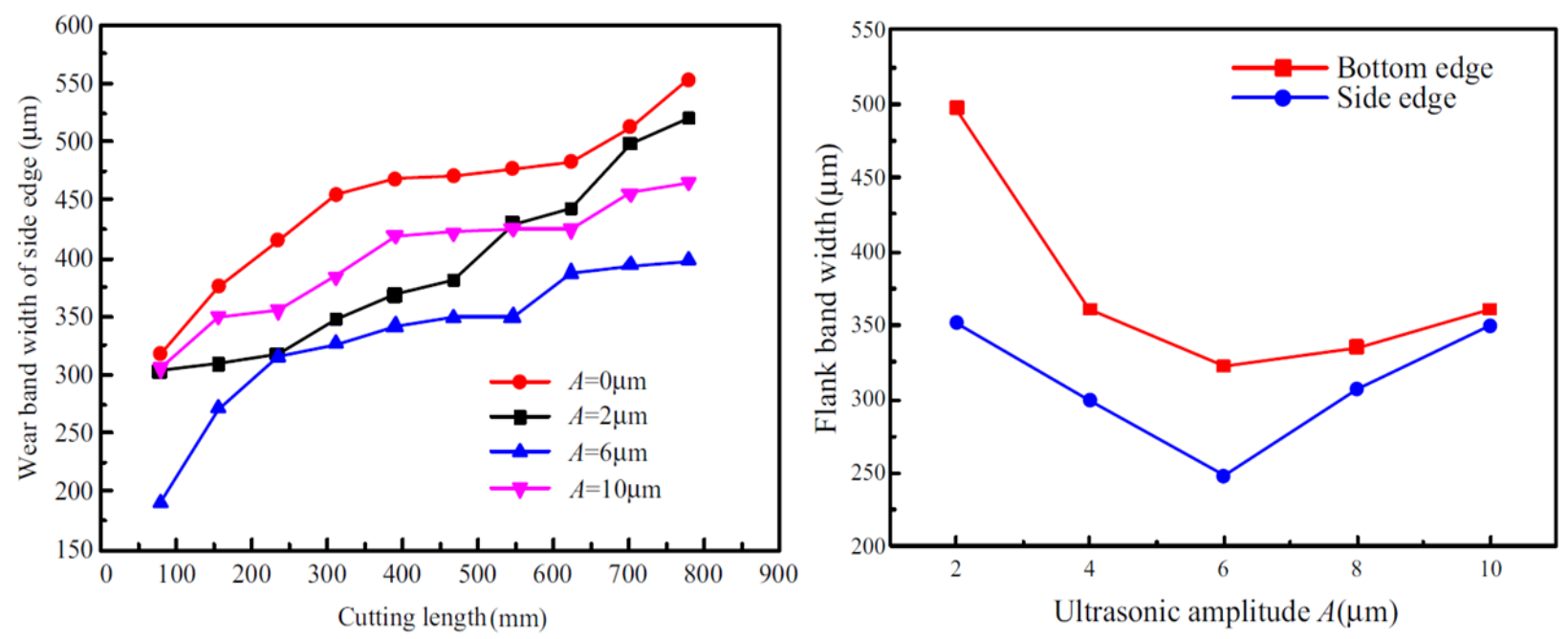

Fig. 35. Tool wear curve and effect of ultrasonic amplitude on tool wear [62] 
The machined surface roughness has a strong negative correlation with specific milling energy. When the feed rate is small, micro brittle fracture occurred under tool extrusion, resulting in large cutting energy, but small roughness (see Fig. 36). Increasing the feed rate induces transformation of material removal mechanism. Macro brittle fracture results in small specific milling energy, but large roughness. Again, the appropriate tool VAM amplitude promotes the initiation and propagation of micro-cracks, thus helps the material to be removed by micro brittle fracture and effectively reduces the machined surface roughness, but an excessive tool amplitude had the opposite effect [63] (Fig. 36).
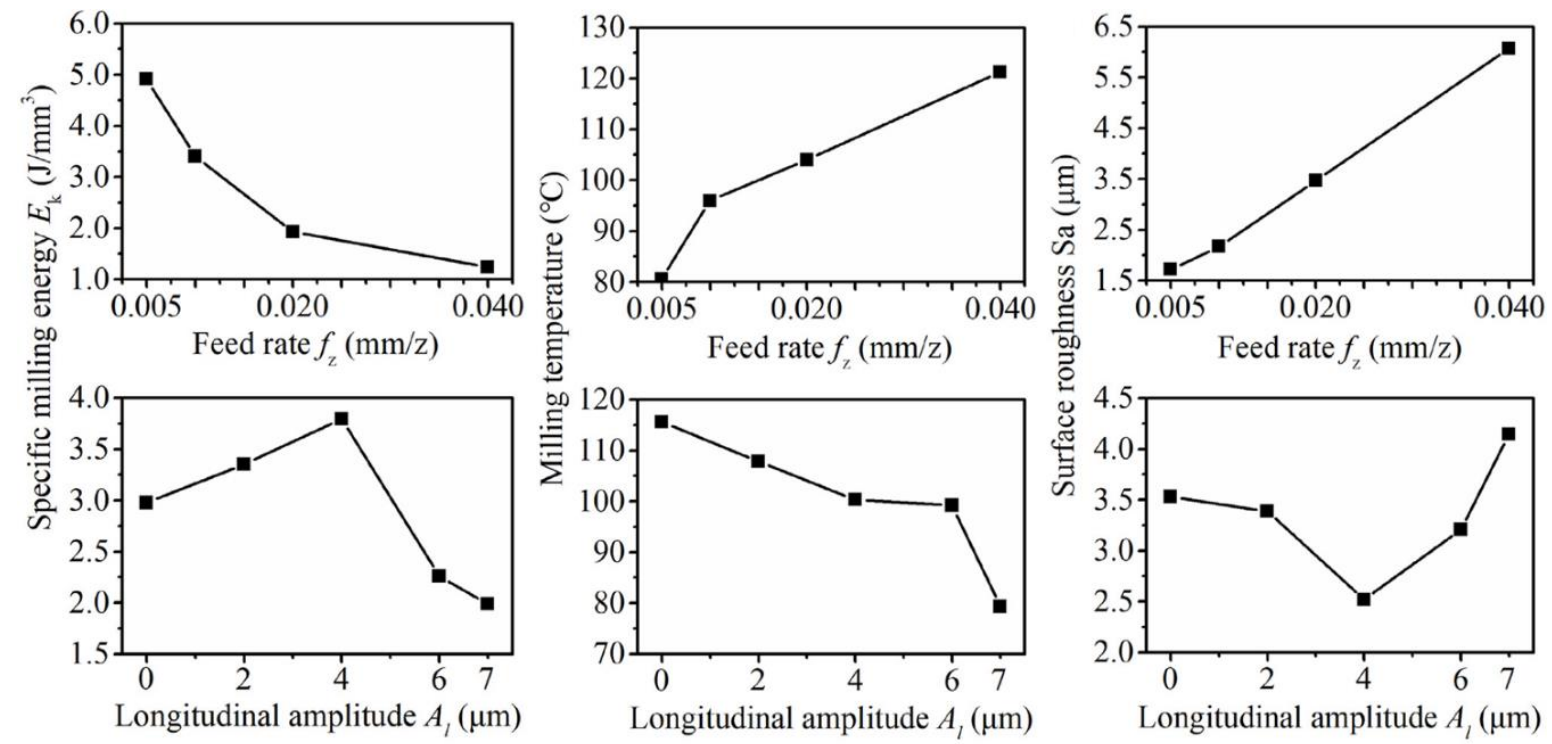

Fig. 36. Effect of feed rate and longitudinal amplitude on specific milling energy, milling temperature and surface roughness [63]

Silicon carbide particulate reinforced aluminum ( $\mathrm{SiCp} / \mathrm{Al}$ ) matrix composites play an important role in aviation, aerospace, electronics, automobile, and other fields due to their outstanding mechanical properties. However, the existence of reinforcing $\mathrm{SiC}$ particles leads to poor cutting performance, terrible surface quality, and severe tool wear of $\mathrm{SiCp} / \mathrm{Al}$ composites. The results of an experimental analysis of VAM and conventional turning of $25 \%$ $\mathrm{SiCp} / \mathrm{Al}$ show substantial decrease in cutting forces, a reduction in machined surface roughness [64]. Experimental results of VAM application in milling of $20 \% \mathrm{SiCp} / \mathrm{Al}$ indicate that the increase of amplitude has little effect on cutting force and surface roughness. However, when the amplitude increases to $3 \mu \mathrm{m}$, the cutting force and surface roughness suddenly increases. Thus, VAM amplitude $3 \mu \mathrm{m}$ can be used as the critical cutting parameter to process $20 \% \mathrm{SiCp} / \mathrm{Al}$ composites for reference in subsequent studies [65].

The use of lightweight materials such as CFRP/Ti6Al4V in stacked structures in the aerospace industry is associated with improved physical and mechanical properties. However, drilling process of heterogeneous structures is usually connected with unacceptable CFRP delamination, hole accuracy and high tool wear. These machining difficulties result from high thermal load and poor chip evacuation. Low-frequency vibration-assisted drilling (LF-VAD) promises a high potential for overcoming these challenges Compared with conventional 
drilling (CD), LF-VAD (2.5 cycle/rev) produces a dynamic change of uncut chip thickness which improves chip evacuation [66] (Fig. 37), reduces the machining thermal load and flank wear, enhances geometrical accuracy [67] (Fig. 38), and reduces entry and exit delamination for all the investigated machining parameters [68] (Fig. 39).
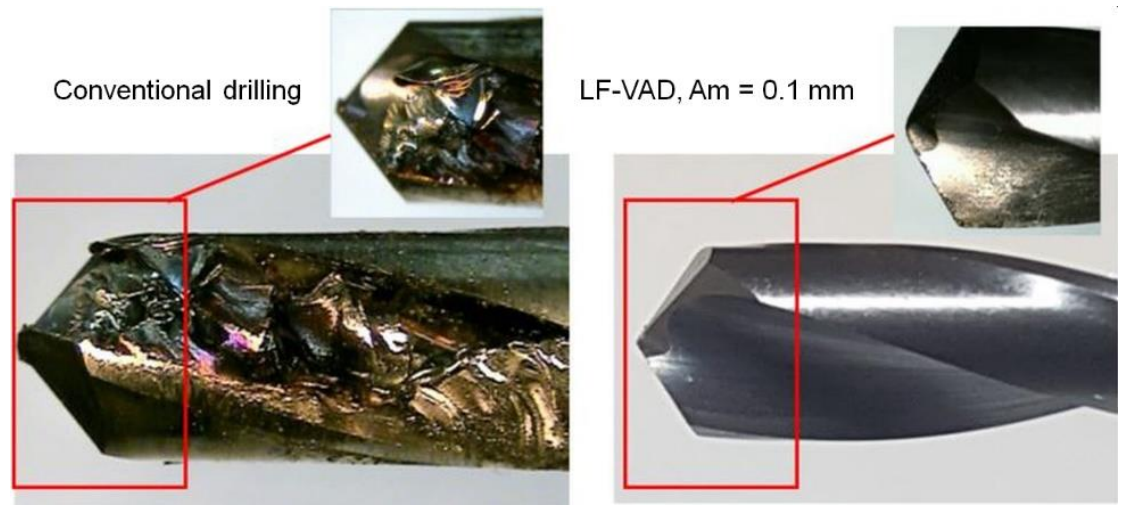

Fig. 37. The effect of cutting technique on cutting tool during CFRP/Ti6Al4V stack material [66]
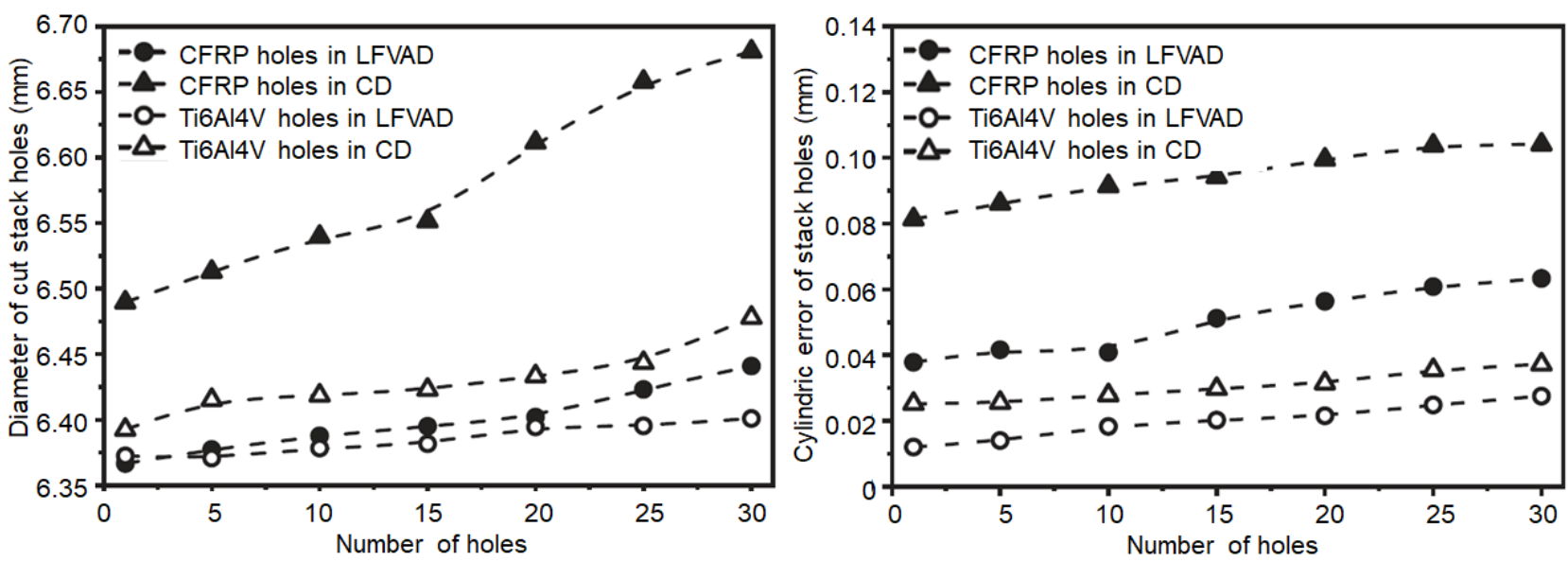

Fig. 38. Comparison of hole diameters and cylindricity errors of cut CFRP/Ti6Al4V stacks between the LFVAD and $\mathrm{CD}$ processes in terms of the number of holes [67]
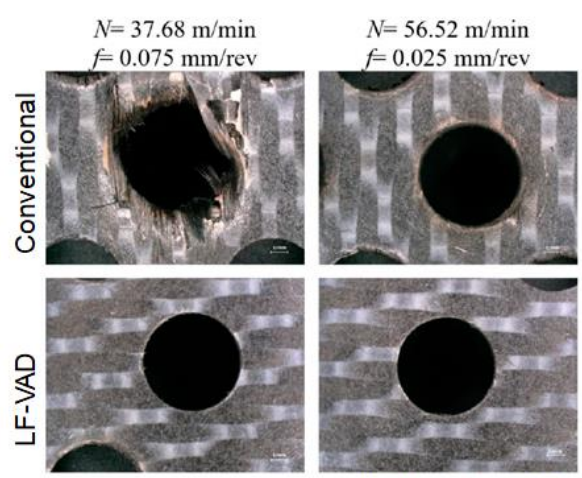

Entry delamination
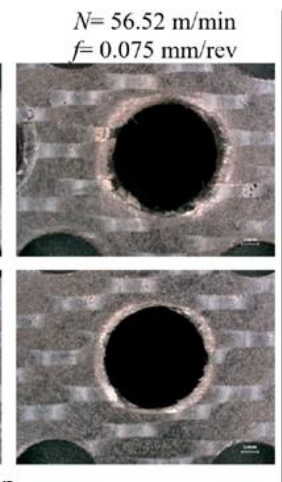
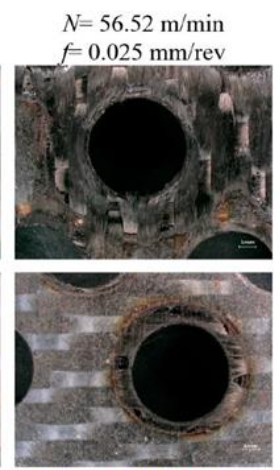

Exit delamination

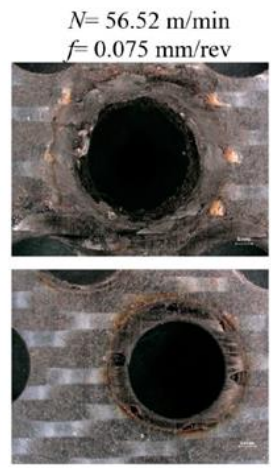

Fig. 39. The effect of machining technique on entry and exit delamination; the end of each machining parameter [68] 
Apart from the positive effects of LF-VAD discussed above, an interesting effect was observed for CFRP/Ti stacks, where CFRP plate, and Ti plate individually were taken under LF-VAD and CD processes. Due to the change in the resultant cutting speed angle and the undeformed chip thickness, LF-VAD produces the longer tool-workpiece contact length on the rake face and the flank face, which directly leads to a more uniform tool wear and a self-sharpening effect on the cutting edge. The drill used in LF-VAD has the less total wear volume, more uniform tool wear distribution, bigger rake angle, bigger clearance angle, smaller wedge angle, and smaller edge radius. In particular, the smaller rotation radius, the stronger the self-sharpening effect [69] (Fig. 40).

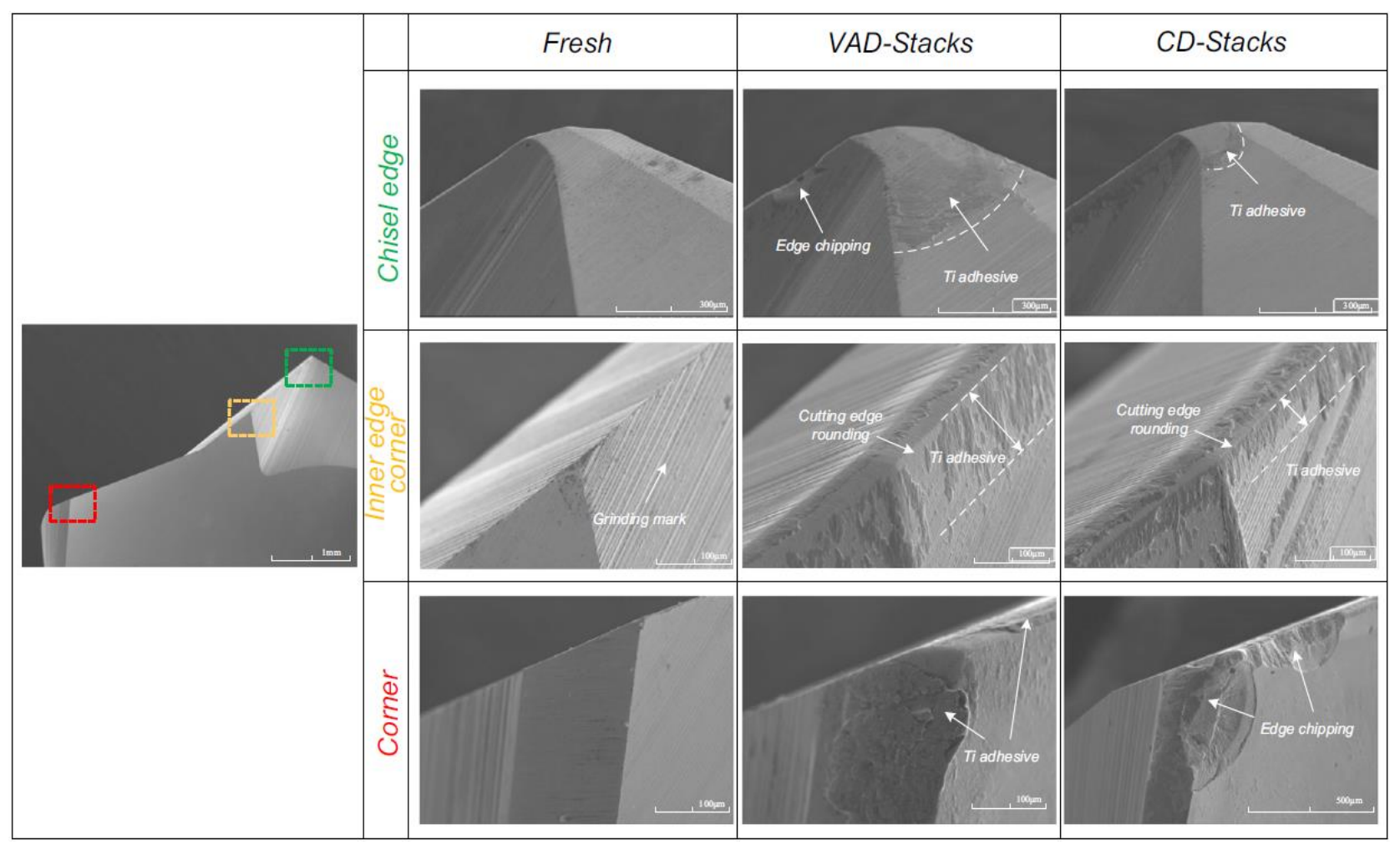

Fig. 40. Comparisons of tool wear patterns for the drills used in CFRP/Ti stack drilling [69]

Application of high frequency vibration-assisted drilling (HF-VAD, here 1500 $2150 \mathrm{~Hz}, 32-65$ cycle/rev) to the as CFRP/Ti6Al4V stacks showed up to $26 \%, 37 \%$, and 86\% reduction in the thrust force, cutting temperature and the exit burr height compared to CD. It also resulted in free exit delamination of CFRP with compressive residual stress on the Ti6Al4V machined surface which can increase the machined part fatigue life [70].

Investigations of the performance of ultrasonic-assisted drilling (UAD) in machining of Ti6Al4V/Al2024T351 laminated material showed that UAD can produce fragile chips, smaller layer delamination, lower thrust force, larger maximum temperature, and lower effective stress [71]. Ultrasound produces high local energy in the workpiece, which can be accomplished with less drilling force. The maximum temperature of the UAD titanium layer and aluminum layer was increased by $6.2 \%$ and $10.3 \%$ respectively. The heat produced by ultrasonic vibration cannot be rapidly diffused, resulting in the increase of tool temperature. 
The equivalent stress of the UCD titanium layer and aluminum layer was reduced by $23.1 \%$ and $31.3 \%$, respectively, reducing tool wear (Fig. 41).
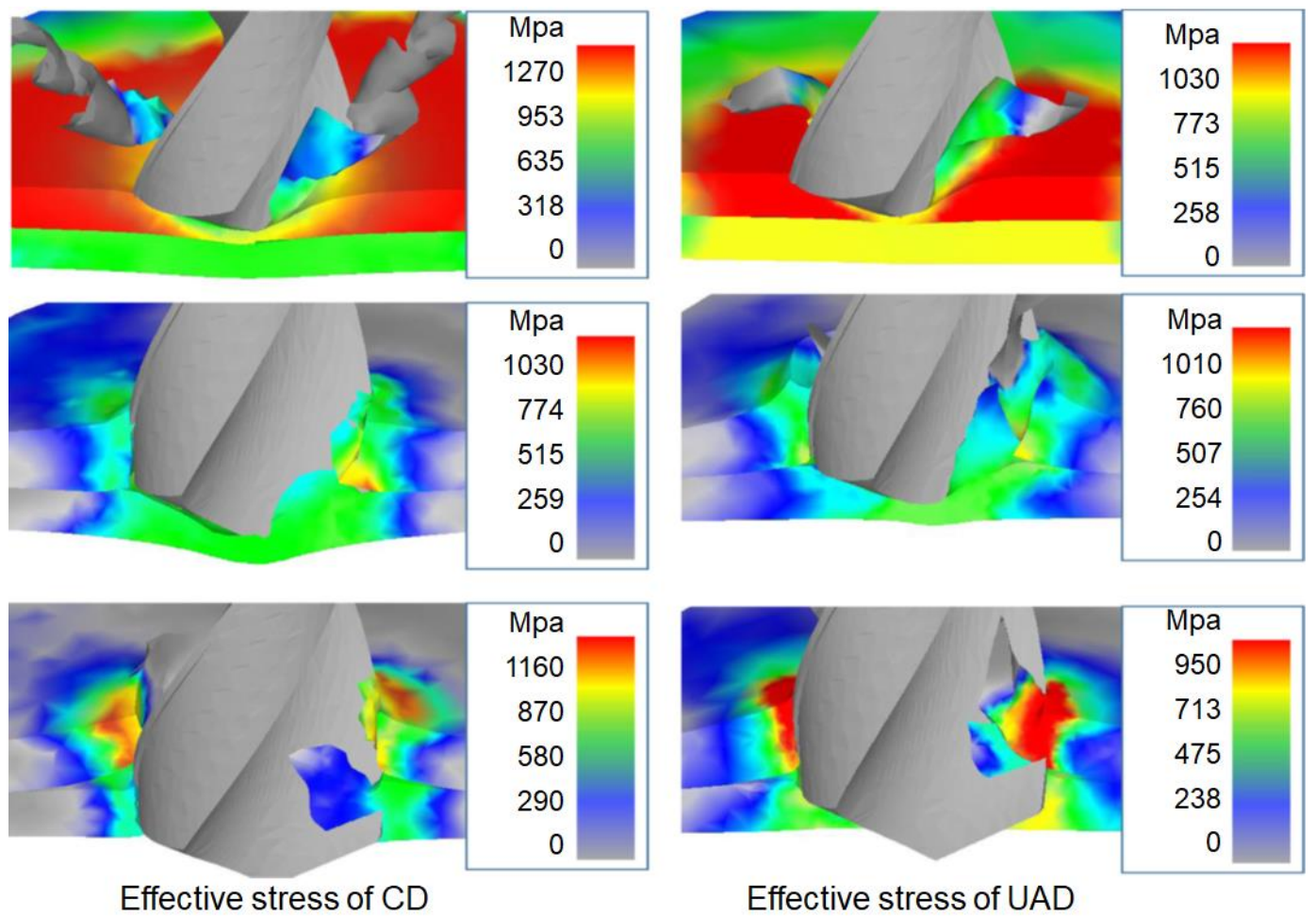

Fig. 41. The equivalent stress diagram of conventional drilling (CD) and ultrasonic-assisted drilling (UAD) at different positions (cut the workpiece through the center of the circle) [71]

\subsection{LASER, PLASMA AND EDM ASSISTED MACHINING}

Laser-assisted milling (LAMill), which uses laser to locally heat the workpiece to improve the machinability of the material, has the advantage of increasing machining efficiency, reducing tool wear, and improving machining quality. The LAMill is particularly popular for the machining of Inconel 718, where there are three softening mechanisms responsible for improving the machinability of the material. Firstly, the temperature of material pre-heated by the laser can reach $600-650^{\circ} \mathrm{C}$ in the shear zone which results in a significant decrease in yield strength. It is also important for elimination of the hardening of the surface by previous passes. Finally, in the case of precipitated Inconel 718, laser heating reduces the hardness of the base material by annealing it.

In the LAMill process machined surface integrity is affected by the combination of pure laser scanning (LS) and conventional milling (CMill) [72] (Fig. 42). This gives the possibility to study the influence of three different processes independently. While the high temperature affected layer in LAM process is removed through the cutting chips, a combined impact of the residual stress from LS and CMill has been found on LAMill workpiece (Fig. 43). The existing extensive tensile residual stress in the deep subsurface of LAMill sample leads 
to the noticeable crack, which is attributed to the failure of LAMill machined workpiece. Although the fatigue life of LAMill machined test pieces is not as good as CMill generated ones, the LAMill proves advantageous in reducing cutting force and improvement of material removal rates. Therefore, the LAMill presents the potential for roughing machining, but knowing the depths that is altered negatively (e.g., fatigue life), a subsequent finishing process or post-processed (e.g., shot peening) can be performed if needed [72].

a)

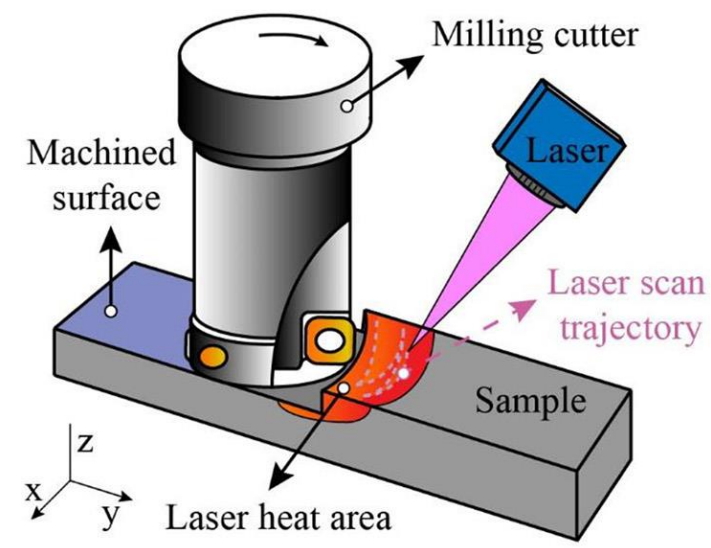

b)

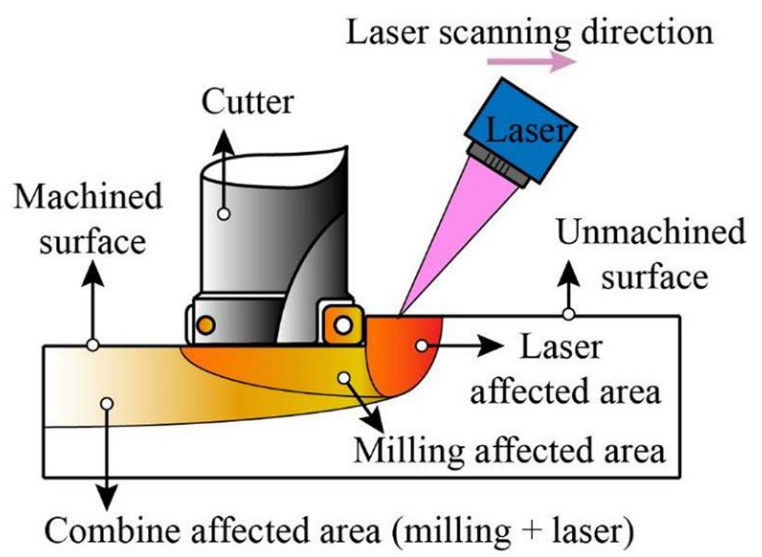

Fig. 42. Heating effect of Laser-assisted milling (LAMill) process; a) laser scanning trajectory for uniformly 3D heating the workpiece; b) heat influenced superficial layer [72]
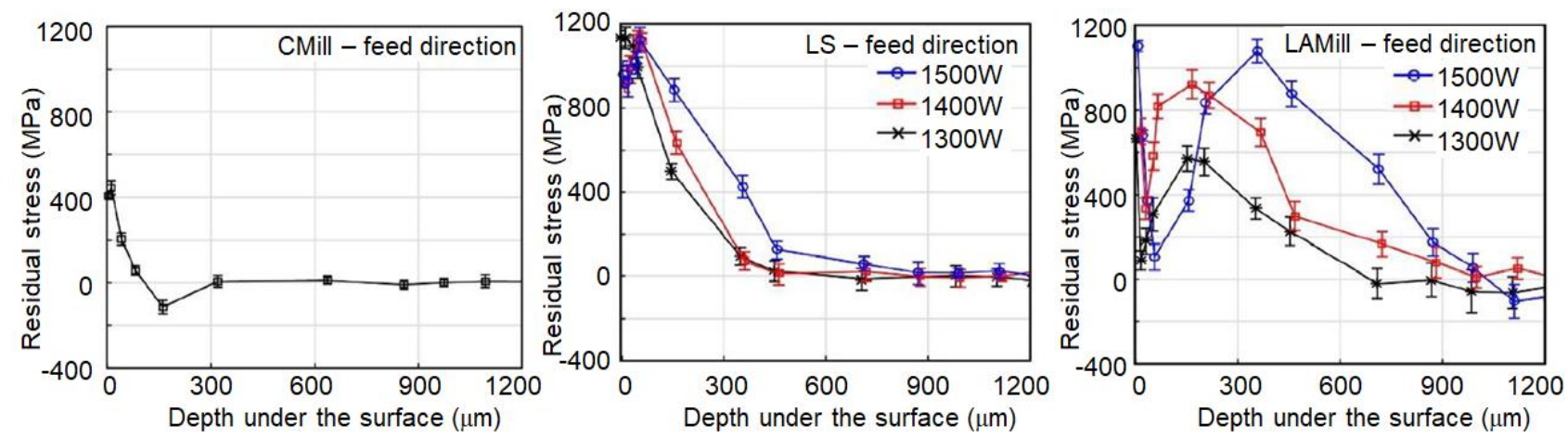

Fig. 43. Comparison of generated residual stresses by conventional milling (CMill), pure laser scanning (LS) and a combination of both: laser-assisted milling (LAMill) [72]

In LAM, laser preheating temperature is the most important parameter influencing laser heating effect; however, constant laser energy commonly used in experiments cannot provide a stable preheating temperature. In the LAMill of Inconel 718, high temperature generated by laser irradiation has a serious effect on the surface ablation. When the temperature of infrared thermometer is more than $750^{\circ} \mathrm{C}$, the surface produces burnout and local deformation. So, the laser heating temperature should be controlled at $750^{\circ} \mathrm{C}$ using a laser power as control parameters to stable the heating temperature [74] (Fig. 44).

Laser assisted milling is relatively expensive, hence other cheaper ways of heating the material are sought after. A plasma heat source has been widely used for welding, melting, 
preheating, etc., and at a cost of about one tenth that of a laser heat source. Comparison of LAMill with the use of plasma heating (PAM) during milling of Inconel 718 showed that PAM reduces the cutting forces by $57 \%$ and the surface roughness of the machined surface by $82 \%$ in relation to conventional machining, while in relation to LAMill these values were only higher by $9 \%$ and $4 \%$ respectively [74].
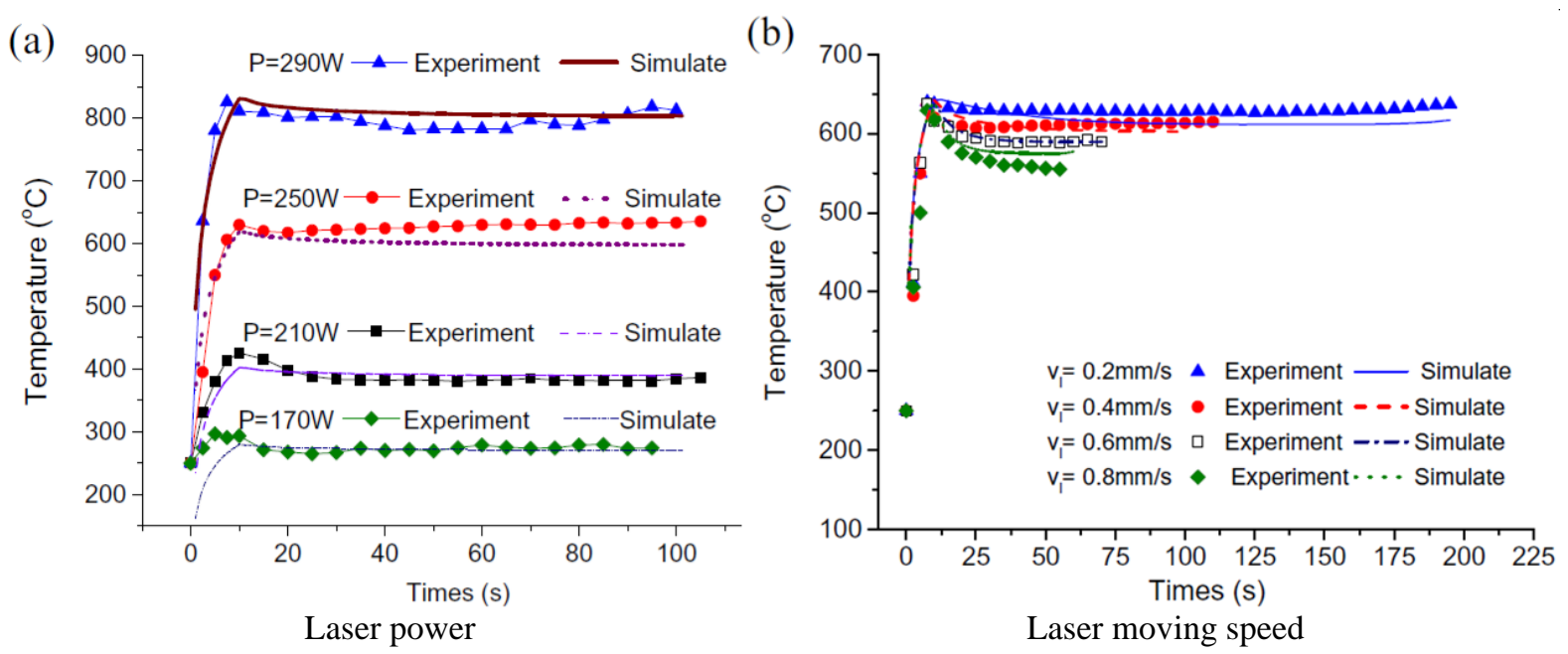

Fig. 44. The influences of laser power and laser moving speed on the measured temperature [73]

Another alternative way to heat up the workpiece material is EDM. Electrical dischargeassisted milling (EDAM) applied for Ti6Al4V significantly reduced the tool wear and cutting force compared to conventional milling. The surface roughness was also greatly improved [75].
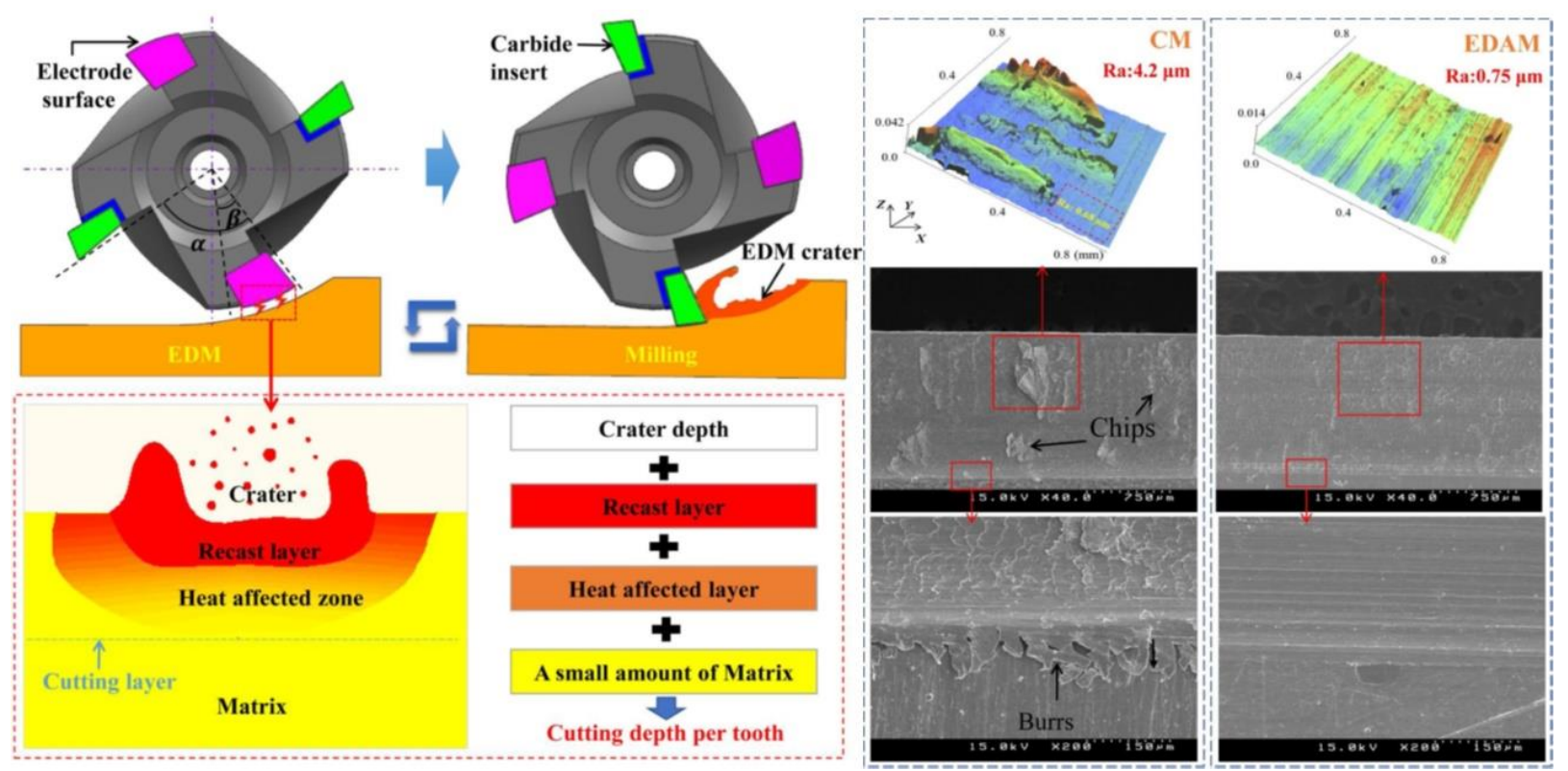

Fig. 45. The principles of EDAM (on the left) and 3D and SEM images of surface morphology of the workpiece after conventional milling and EDAM of Ti6Al4V (on the right) [75] 


\section{CONCLUSIONS}

Highly efficient and environmentally friendly cooling and hybrid processing methods have been used to process aerospace materials for several years. Recently, however, there has been a significant acceleration in the development of these techniques, as well as in their combination, which significantly improves their efficiency through synergistic effects. Minimum quantity lubrication (MQL) has been combined with cryogenic cooling (CryoMQL) and additionally enhanced with nano-additives.

In addition to the known advantages of ultrasonic vibration-assisted machining (VAM), the combination of VAM with MQL (VAM\&MQL) has increased their effectiveness in reducing surface roughness, temperature, and cutting forces, and has made it possible to avoid the formation of health-hazardous oil mist. Adding vibration to high-pressure cooling, as with VAM\&MQL, facilitated coolant access to the cutting edge further improving the efficiency of aerospace alloys machining.

Despite considerable, impressive achievements, the techniques described here still cannot be considered mastered, easy to apply. Careful selection of process parameters is necessary in each individual case. Nevertheless, further rapid development of methods of aerospace materials processing should be expected, so it is worth following the current literature reports.

\section{REFERENCES}

[1] LAUWERS B., KLOCKE F., KLINK A., TEKKAYA A.E., NEUGEBAUER R., MCINTOSH D., 2014, Hybrid Processes in Manufacturing, CIRP Annals - Manufacturing Technology, 63, 561-583.

[2] M'SAOUBI R., AXINTE R., SOO S.L, NOBEL C., ATTIA H., KAPPMEYER G., ENGIN S., SIM W.M., 2015, High Performance Cutting of Advanced Aerospace Alloys and Composite Materials, CIRP Annals Manufacturing Technology, 64, 557-580.

[3] CHEN W., HUO D., SHI Y., HALE J.M., 2018, State-of-the-Art Review on Vibration-Assisted Milling: Principle, System Design, and Application, Int. J. Adv. Manuf. Technol., 97, 2033-2049.

[4] DESHPANDE Y.V., ANDHARE A.B., PADOLE P.M., 2018, How Cryogenic Techniques Help in Machining of Nickel Alloys? A review, Machining Science and Technology, 22/4, 543-584.

[5] LI J., RASHID L., LAGHARI A., 2019, A Review on Machining and Optimization of Particle-Reinforced Metal Matrix Composites, Int. J. Adv. Manuf. Technol., 100, 2929-2943.

[6] OSMAN K.A., ÜNVER H.Ö., ŞEKER U., 2019, Application of Minimum Quantity Lubrication Techniques in Machining Process of Titanium Alloy for Sustainability: a review, Int. J. Adv. Manuf. Technol., 100, $2311-2332$.

[7] PERVAIZ S., ANWAR S., QURESHI I., AHMED N., 2019, Recent Advances in the Machining of Titanium Alloys using Minimum Quantity Lubrication (MQL) Based Techniques, International Journal of Precision Engineering and Manufacturing-Green Technology, 6, 133-145.

[8] SAID Z., GUPTA M., HEGAB H., ARORA N., KHAN A.M., JAMIL M., BELLOS E., 2019, A Comprehensive Review on Minimum Quantity Lubrication (MQL) in Machining Processes Using Nano-Cutting Fluids, Int. J. Adv. Manuf., Technol., 105, 2057-2086.

[9] FAN W., JI W., WANG L., ZHENG L., WANG Y., 2020, A Review on Cutting Tool Technology in Machining of Ni-Based Superalloys, Int. J. Adv. Manuf. Technol., 110, 2863-2879.

[10] ROSS K.N.S, MANIMARAN G., 2019, Effect of Cryogenic Coolant on Machinability of Difficult-to-Machine $\mathrm{Ni-Cr}$ Alloy Using PVD-TiAlN Coated WC Tool, Journal of the Brazilian Society of Mechanical Sciences and Engineering, 41, 44.

[11] PUŠAVEC F., GRGURAŠ D., KOCH M., KRAJNIK P., 2019, Cooling Capability of Liquid Nitrogen and Carbon Dioxide in Cryogenic Milling, CIRP Annals - Manufacturing Technology, 68, 73-76. 
[12] JAMIL M., KHAN A.M., GUPTA M.K., MIA M., HE N., LI, L., SIVALINGAM V., 2020, Influence of CO2Snow and Subzero MQL on Thermal Aspects in the Machining of Ti-6Al-4V, Applied Thermal Engineering, 177, 115480.

[13] DAMIR A., SADEK A., ATTIA H., 2018, Characterization of Machinability and Environmental Impact of Cryogenic Turning of Ti-6Al-4V, Procedia CIRP, 69, 893-898.

[14] JAWAHIR I.S., ATTIA H., BIERMANN D., DUFLOU J., KLOCKE F., MEYER D., NEWMAN S.T., PUSAVEC F., PUTZ M., RECH J., SCHULZE V., UMBRELLO D., 2016, Cryogenic Manufacturing Processes, CIRP Annals - Manufacturing Technology, 65, 713-736.

[15] SHAH P., KHANNA N., CHETAN A., 2020, Comprehensive Machining Analysis to Establish Cryogenic LN2 and LCO2 As Sustainable Cooling and Lubrication Techniques, Tribology International, 148, 106314.

[16] CHETAN A., KHANNA N., PRUNCU C.I, Singla A.K, Gupta M.K, 2020, Tool Wear Progression and Its Effects on Energy Consumption and Surface Roughness in Cryogenic Assisted Turning of Ti-6Al-4V, Int. J. Adv. Manuf., Technol., 111, 1319-1331.

[17] CHAABANI S., ARRAZOLA P.J., AYED Y., MADARIAGA A., TIDU A., GERMAIN G., 2020, Comparison Between Cryogenic Coolants Effect on Tool Wear and Surface Integrity in Finishing Turning of Inconel 718, Journal of Materials Processing Tech., 285, 116780.

[18] SARTORI S., PEZZATO L., DABALÀ M., ENRICI T.M., MERTENS A., GHIOTTI A., BRUSCHI S., 2018, Surface Integrity Analysis of Ti6Al4V After Semi-finishing Turning Under Different Low-Temperature Cooling Strategies, Journal of Materials Engineering and Performance, 27, 4810-4818.

[19] SARTORI S., TACCIN M., PAVESE G., GHIOTTI A., BRUSCHI S., 2018, Wear Mechanisms of Uncoated and Coated Carbide Tools When Machining Ti6Al4V Using LN2 and Cooled N2, Int. J. Adv. Manuf. Technol., 95, $1255-1264$.

[20] KIRSCH B., BASTEN S., HASSE H., AURICH J.C, 2018, Sub-Zero Cooling: A Novel Strategy for High Performance Cutting, CIRP Annals - Manufacturing Technology, 67, 95-98.

[21] STAMPFER B., GOLDA P., SCHIEßL R., MAAS U., SCHULZE V., 2020, Cryogenic Orthogonal Turning of Ti-6Al-4V, Int. J. Adv. Manuf. Technol., 111, 359-369.

[22] KUMAR D., GURURAJA S., 2020, Machining Damage and Surface Integrity Evaluation During Milling of UDCFRP Laminates: Dry vs. cryogenic, Composite Structures, 247, 112504.

[23] KANNAN S., PERVAIZ S., 2020, Surface Morphology of Inclined CFRP Holes When Machined Under Cryogenic Environment, Materials and Manufacturing Processes, 35/11, 1228-1239.

[24] OKAFOR A.C., NWOGUH T.O., 2020, Comparative Evaluation of Soybean Oil-Based MQL Flow Rates and Emulsion Flood Cooling Strategy in High-Speed Face Milling of Inconel 718, Int. J. Adv. Manuf. Technol., 107, 3779-3793.

[25] DONG L., LI C., BAI X., ZHAI M., QI Q., YIN Q., LV X., LI L., 2019, Analysis of the Cooling Performance of Ti-6Al-4V in Minimum Quantity Lubricant Milling with Different Nanoparticles, Int. J. Adv. Manuf. Technol., 103, 2197-2206.

[26] HEGAB H., UMER U., SOLIMAN M., KISHAWY H.A., 2018, Effects of Nano-Cutting Fluids on Tool Performance and Chip Morphology During Machining Inconel 718, Int. J. Adv. Manuf., Technol., 96, 3449-3458.

[27] MARQUES A., SUAREZ M.P., SALES W.F., MACHADO Á.R., 2019, Turning of Inconel 718 with WhiskerReinforced Ceramic Tools Applying Vegetable-Based Cutting Fluid Mixed with Solid Lubricants by MQL, Journal of Materials Processing Tech., 266, 530-543.

[28] SIVALINGAM V., ZAN Z., SUN J., SELVAM B., GUPTA M.K., JAMIL M., MIA M., 2020, Wear Behavior of Whisker-Reinforced Ceramic Tools in the Turning of Inconel 718 assisted by an atomized spray of solid lubricants, Tribology International, 148, 106235.

[29] SARTORI S., GHIOTTI A., BRUSCHI S., 2018, Solid Lubricant-Assisted Minimum Quantity Lubrication and Cooling Strategies to Improve Ti6Al4V Machinability in Finishing Turning, Tribology International, 118, 287294.

[30] LI M., YU T., ZHANG R., LI H., WANG W., 2018, MQL Milling of TC4 Alloy by Dispersing Graphene into Vegetable Oil-Based Cutting Fluid, Int. J. Adv. Manuf. Technol., 99, 1735-1753.

[31] GONG L., BERTOLINI R., GHIOTTI A., HE N., BRUSCH S., 2020, Sustainable Turning of Inconel 718 Nickel Alloy Using MQL Strategy Based on Graphene Nanofluids, Int. J. Adv. Manuf. Technol., 108, 3159-3174.

[32] BERTOLINI R., GONG L., GHIOTTI A., BRUSCHI S., 2020, Graphene Nanoplatelets-Assisted Minimum Quantity Lubrication in Turning To Enhance Inconel 718 Surface Integrity, Procedia CIRP, 87, 71-76.

[33] YI S., MO J., DING S., 2019, Experimental Investigation on the Performance and Mechanism of Graphene Oxide Nanofluids in Turning Ti-6Al-4V, Journal of Manufacturing Processes, 43, 164-174.

[34] LI G., YI S., LI N., PAN W., WEN C., DING S., 2019, Quantitative Analysis of Cooling and Lubricating Effects of Graphene Oxide Nanofluids in Machining Titanium Alloy Ti6Al4V, Journal of Materials Processing Tech., 271, 584-598. 
[35] SHOKRANI A., BETTS J., 2020, A New Hybrid Minimum Quantity Lubrication System for Machining Difficultto-Cut Materials, CIRP Annals - Manufacturing Technology, 69, 73-76.

[36] BARTOLOMEIS A.D., SHOKRANI A., 2020, Electrohydrodynamic Atomization for Minimum Quantity Lubrication (EHDA-MQL) in End Milling Ti6Al4V Titanium Alloy, J. Manuf. Mater. Process., 4, 70.

[37] SHOKRANI A., AL-SAMARRAI I., NEWMAN S.T., 2019, Hybrid Cryogenic MQL for Improving Tool Life in Machining of Ti-6Al-4V Titanium Alloy, Journal of Manufacturing Processes, 43, 229-243.

[38] PEREIRA O., CELAYA A., URBIKAÍN G., RODRÍGUEZ A., FERNÁNDEZ-VALDIVIELSO A., LACALLE L.N.L, 2020, CO2 Cryogenic Milling of Inconel 718: Cutting Forces and Tool Wear, Journal of Materials Research and Technology, 9, 8459-8468.

[39] YILDIRIM C.V, KIVAK T., SARIKAYA M., SIRIN S., 2020, Evaluation of Tool Wear, Surface Roughness/Topography and Chip Morphology When Machining of Ni-Based Alloy 625 Under MQL, Cryogenic Cooling and CryoMQL, Journal of Materials Research and Technology, 9/2, 2079-2092.

[40] DAMIR A., SHI B., ATTIA M.H, 2019, Flow Characteristics of Optimized Hybrid Cryogenic-Minimum Quantity Lubrication Cooling in Machining of Aerospace Materials, CIRP Annals - Manufacturing Technology, 68, 77-80.

[41] BAGHERZADEH A., BUDAK E, 2018, Investigation of Machinability in Turning of Difficult-to-Cut Materials Using a New Cryogenic Cooling Approach, Tribology International, 119, 510-520.

[42] SUHAIMI M.A., YANG G.-D., PARK K.H., SHARIF S., KIM D.W., 2018, Effect of Cryogenic Machining for Titanium Alloy Based on Indirect, Internal and External Spray System, Procedia Manufacturing, 17, 158-165.

[43] SCHOOP J., SALES W.F., JAWAHIR I.S., 2017, High Speed Cryogenic Finish Machining of Ti-6Al4V with Polycrystalline Diamond Tools, Journal of Materials Processing Tech., 250, 1-8.

[44] CICA D., KRAMAR D., 2019, Multi-Objective Optimization of High-Pressure Jet-Assisted Turning of Inconel 718, Int. J. Adv. Manuf. Technol., 105, 4731-4745.

[45] KAYNAKA Y., GHARIBI A., YILMAZ U., KÖKLÜ U, ASLANTAŞ K., 2018, A Comparison of Flood Cooling, Minimum Quantity Lubrication and High Pressure Coolant on Machining and Surface Integrity of Titanium Ti5553 alloy, Journal of Manufacturing Processes, 34, 503-512.

[46] TASCIOGLU E., GHARIBI A., KAYNAK Y., 2019, High Speed Machining of Near-Beta Titanium Ti-5553 Alloy Under Various Cooling and Lubrication Conditions, Int. J. Adv. Manuf. Technol., 102, 4257-4271.

[47] SØRBY K., VAGNORIUS Z., 2018, High-Pressure Cooling in Turning of Inconel 625 with Ceramic Cutting Tools, Procedia CIRP, 77, 74-77.

[48] SUÁREZ A., VEIGA F., DE LACALlE L.N.L., POLVOROSA R., WRETLAND A., 2019, An Investigation of Cutting Forces and Tool Wear in Turning of Haynes 282, Journal of Manufacturing Processes, 37, 529-540.

[49] ZHENG L., CHEN W., HUO D., 2020, Review of vibration devices for vibration-assisted machining, Int. J. Adv. Manuf. Technol., 108, 1631-1651.

[50] RINCK P.M., GUERAY A., KLEINWORT R., ZAEH M.F, 2020, Experimental Investigations on LongitudinalTorsional Vibration-Assisted Milling of Ti-6Al-4V, Int. J. Adv. Manuf., Technol., 108, 3607-3618.

[51] LIU Q., XU J., YU H., 2020, Experimental Study of Tool Wear and Its Effects on Cutting Process of UltrasonicAssisted Milling of Ti6Al4V, Int. J. Adv. Manuf., Technol., 108, 2917-2928.

[52] ZHU L., NI C., YANG Z., LIU C., 2019, Investigations of Microtextured Surface Generation Mechanism and Tribological Properties in Ultrasonic Vibration-Assisted Milling of Ti-6Al-4V, Precision Engineering, 57, 229243.

[53] GAO J., JIN X., 2019, Effects of Ultrasonic Vibration Assistance on Chip Formation Mechanism in Cutting of Ti-6Al-4V, J. Manuf. Sci. Eng., 141/12, 121007.

[54] HUSSEIN R., SADEK A., ELBESTAWI M. A., ATTIA M.H., 2019, Surface and Microstructure Characterization of Low-Frequency Vibration-Assisted Drilling of Ti6Al4V, Int. J. Adv. Manuf., Technol., 103, 1443-1457.

[55] HUSSEIN R., SADEK A., ELBESTAWI M.A., ATTIA M.H., 2020, Effect of Process Parameters on Chip formation during vibration-assisted drilling of Ti6Al4V, Int. J. Adv. Manuf., Technol., 106, 1105-1119.

[56] SINGH M., DHIMAN S., SINGH H., BERNDT C.C., 2020, Optimization of Modulation-Assisted Drilling of Ti6Al-4V Aerospace Alloy Via Response Surface Method, Materials and Manufacturing Processes, 35/12, 1313-1329

[57] BAI W., BISHT A., ROY A., SUWAS S., SUN R., SILBERSCHMIDT V.V, 2019, Improvements of Machinability of Aerospace-Grade Inconel Alloys with Ultrasonically Assisted Hybrid Machining, Int. J. Adv. Manuf., Technol., 101, 1143-1156.

[58] YAN L., ZHANG Q., YU J., 2018, Effects of Continuous Minimum Quantity Lubrication with Ultrasonic Vibration in Turning of Titanium Alloy, Int. J. Adv. Manuf., Technol., 98, 827-837.

[59] NI C., ZHU L., YANG Z., 2019, Comparative Investigation of Tool Wear Mechanism and Corresponding Machined Surface Characterization in Feed-Direction Ultrasonic Vibration Assisted Milling of Ti-6Al-4V from Dynamic View, Wear, 436-437, 203006. 
[60] NI C., ZHU L., 2020, Investigation on Machining Characteristics of TC4 Alloy by Simultaneous Application of Ultrasonic Vibration Assisted Milling (UVAM) and Economical-Environmental MQL Technology, Journal of Materials Processing Tech., 278, 116518.

[61] LU Z., ZHANG D., ZHANG X., PENG Z., 2020, Effects of High-Pressure Coolant on Cutting Performance of High-Speed Ultrasonic Vibration Cutting Titanium Alloy, Journal of Materials Processing Tech., $279,116584$.

[62] LIU Y., LIU Z., WANG X., HUANG T., 2020, Experimental Study on Tool Wear in Ultrasonic Vibration-Assisted Milling of C/SiC Composites, Int. J. Adv. Manuf. Technol., 107, 425-436.

[63] CHEN J., MING W., AN Q., CHEN M., 2020, Mechanism and Feasibility of Ultrasonic-Assisted Milling to Improve the Machined Surface Quality of 2D Cf/SiC Composites, Ceramics International, 46, 15122-15136.

[64] KIM J., BAI W., ROY A., JONES L.C.R, AYVAR-SOBERANIS S., SILBERSCHMIDT V.V., 2019, Hybrid Machining of Metal-Matrix Composite, Procedia CIRP, 82, 184-189.

[65] NIU Q., JING L, WANG C., LI S., QIU X., LI C., XIANG D., 2020, Study on Effect of Vibration Amplitude on Cutting Performance of SiCp/Al Composites During Ultrasonic Vibration-Assisted Milling, Int. J. Adv. Manuf., Technol., 106, 2219-2225.

[66] HUSSEIN R., SADEK A., ELBESTAWI M. A., ATTIA M.H., 2018, Low-Frequency Vibration-Assisted Drilling of Hybrid CFRP/Ti6Al4V Stacked Material, Int. J. Adv. Manuf. Technol., 98, 2801-2817.

[67] XU J., LI C., CHEN M., REN F., 2019, A Comparison Between Vibration Assisted and Conventional Drilling of CFRP/Ti6Al4V Stacks, Materials and Manufacturing Processes., 34/10, 1182-1193.

[68] HUSSEIN R., SADEK A., ELBESTAWI M.A., ATTIA M.H., 2019, An Investigation into Tool Wear and Hole Quality During Low-Frequency Vibration-Assisted Drilling of CFRP/Ti6Al4V stack, J. Manuf., Mater. Process., $3 / 3,63$.

[69] YANG H., CHEN Y., XU J., LADONNE M., LONFIER J., FU Y., 2019, Tool Wear Mechanism in LowFrequency Vibration-Assisted Drilling of CFRP/Ti Stacks and Its Individual Layer, Int. J. Adv Manuf. Technol., 104, 2539-2551.

[70] HUSSEIN R., SADEK A., ELBESTAWI M.A., ATTIA M.H., 2019, Elimination of Delamination and Burr Formation Using High-Frequency Vibration-Assisted Drilling of Hybrid CFRP/Ti6Al4V Stacked Material, Int. J. Adv. Manuf., Technol., 105, 859-873.

[71] WEI L., WANG D., 2019, Comparative Study on Drilling Effect Between Conventional Drilling and UltrasonicAssisted Drilling of Ti-6Al-4V/Al2024-T351 Laminated Material, Int. J. Adv. Manuf. Technol., 103, 141-152.

[72] XU D., LIAO Z., AXINTE D., SARASUA J.A., WRETLAND A., 2020, Investigation of Surface Integrity in Laser-Assisted Machining of Nickel Based Superalloy, Materials and Design, 194, 108851.

[73] WU X., CHEN J., 2018, The Temperature Process Analysis and Control on Laser-Assisted Milling of NickelBased Superalloy, Int. J. Adv. Manuf. Technol., 98, 223-235.

[74] MOON S-H., LEE C-M., 2018, A Study on the Machining Characteristics Using Plasma Assisted Machining of AISI 1045 Steel and Inconel 718, International Journal of Mechanical Sciences, 142/143, 595-602.

[75] LI C., XU M., YU Z., HUANG L., LI S., LI P., NIU Q., KO T.J., 2020, Electrical Discharge-Assisted Milling for Machining Titanium Alloy, Journal of Materials Processing Tech., 285, 116785. 